IZA DP No. 6773

Water Scarcity and Birth Outcomes in the Brazilian Semiarid

Rudi Rocha

Rodrigo R. Soares

July 2012 


\title{
Water Scarcity and Birth Outcomes in the Brazilian Semiarid
}

\author{
Rudi Rocha \\ UFRJ \\ Rodrigo R. Soares \\ PUC-Rio and IZA
}
Discussion Paper No. 6773
July 2012

IZA
P.O. Box 7240
53072 Bonn
Germany

Phone: +49-228-3894-0

Fax: +49-228-3894-180

E-mail: iza@iza.org

\begin{abstract}
Any opinions expressed here are those of the author(s) and not those of IZA. Research published in this series may include views on policy, but the institute itself takes no institutional policy positions.

The Institute for the Study of Labor (IZA) in Bonn is a local and virtual international research center and a place of communication between science, politics and business. IZA is an independent nonprofit organization supported by Deutsche Post Foundation. The center is associated with the University of Bonn and offers a stimulating research environment through its international network, workshops and conferences, data service, project support, research visits and doctoral program. IZA engages in (i) original and internationally competitive research in all fields of labor economics, (ii) development of policy concepts, and (iii) dissemination of research results and concepts to the interested public.
\end{abstract}

IZA Discussion Papers often represent preliminary work and are circulated to encourage discussion. Citation of such a paper should account for its provisional character. A revised version may be available directly from the author. 


\section{ABSTRACT}

\section{Water Scarcity and Birth Outcomes in the Brazilian Semiarid}

This paper analyzes the impact of rainfall fluctuations during the gestational period on health at birth. We concentrate on the semiarid region of Northeastern Brazil to highlight the role of water scarcity as a determinant of early life health. We find that negative rainfall shocks are robustly correlated with higher infant mortality, lower birth weight, and shorter gestation periods. Mortality effects are concentrated on intestinal infections and malnutrition, and are greatly minimized when the local public health infrastructure is sufficiently developed (municipality coverage of piped water and sanitation). We also find that effects are stronger during the fetal period ( $2^{\text {nd }}$ trimester of gestation), for children born during the dry season, and for mortality in the first 6 months of life. The results seem to be driven by water scarcity per se, and not by reduced agricultural production. Our estimates suggest that expansions in public health infrastructure would be a cost-effective way of reducing the response of infant mortality to rainfall shocks in the Brazilian semiarid.

\section{JEL Classification: I15, I18, H51, Q54}

Keywords: $\quad$ water, rainfall, health, birth, infant mortality, sanitation, semiarid, Brazil

Corresponding author:

Rodrigo R. Soares

Departamento de Economia

Pontifícia Universidade Católica do Rio de Janeiro

Rua Marquês de São Vicente, 225 - Gávea

22451-900 Rio de Janeiro, RJ

Brazil

E-mail: soares@econ.puc-rio.br

\footnotetext{
* This paper benefited from comments and suggestion from Juliano Assunção, Michel Azulai, Claudio Ferraz, Gustavo Gonzaga, Naercio Menezes-Filho, André Portela Souza, and seminar participants at EESP/FGV-São Paulo, Maastricht University, IPEA-Rio, PIMES/UFPE, PUC-Rio, UFRJ, Universidad de los Andes, Université Catholique de Louvain, the 2011 Meeting of the Brazilian Econometrics Society (Foz do Iguaçu), the 2011 Meeting of the Chilean Economic Society (Viña del Mar), the 2011 Meeting of the Latin American and Caribbean Economic Association (Santiago), and the ZEW Workshop on Health and Human Capital (Mannheim, 2011).
} 
IZA Discussion Paper No. 6773

July 2012

\section{NON-TECHNICAL SUMMARY}

Arid and semiarid regions encompass 54\% of the developing world's agricultural area and one-third of its rural population. Close to 1 billion people today, among the poorest in the planet, live in regions characterized by recurrent moisture stress. A large fraction of this population has inadequate access to water supplies and improved sanitation facilities. An estimated 900 million people in the world today live with inadequate access to water supplies and 2.7 billion live without improved sanitation facilities. For them, collecting water for consumption, hygiene, and agricultural production is a daily task that demands energy and resources. Lack of adequate access to water also increases the susceptibility to climatic shocks associated with fluctuations in rainfall. In a context of poverty and lack of access to insurance mechanisms, these shocks can have serious welfare consequences both in the short and in the long run. Notoriously, water scarcity can reduce agricultural production and nutrient intake, impacting health outcomes. In addition, it can directly lead to increased incidence of infectious diseases, such as diarrhoea, particularly affecting young children and pregnant women.

This paper analyzes the impact of rainfall fluctuations during the gestational period on health at birth. We concentrate on the semiarid region of Northeastern Brazil - the driest region in the country - to highlight the role of water scarcity as a determinant of early life health. This region has long been subject to harsh climatic conditions, with intermittent events of drought, water scarcity and food insecurity. We examine whether and how idiosyncratic shocks to rainfall during the time in utero affect a range of health outcomes at birth, including birth weight, number of weeks of gestation, and infant mortality (by cause of death, gender, season of birth, and time since birth). We also explore the specific channels linking variation in rainfall to health outcomes at birth. In our setting, there are two main potential connections in this relationship: (i) lower agricultural production and lower nutrient intake; and (ii) lack of safe drinkable water and higher incidence of infectious diseases.

Our results indicate that negative rainfall shocks are robustly correlated with higher infant mortality, lower birth weight, and shorter gestation periods. Mortality effects are concentrated on intestinal infections and malnutrition, and are greatly minimized when the local public health infrastructure is sufficiently developed. Conditional on income, the estimated impact of rainfall fluctuation decreases monotonically with municipality coverage of piped water and sanitation, losing statistical significance when coverage of these public goods is high enough. At the same time, results do not seem to be associated with agricultural production, remaining virtually unchanged when we control for production per capita in the years surrounding birth. We also find that effects are stronger during the fetal period $\left(2^{\text {nd }}\right.$ trimester of gestation) and for children born during the dry season. Overall, our results seem to be capturing the effects of scarcity of drinkable water per se, and not reduced agricultural production, on birth outcomes. Apart from its own relevance, this evidence is also important in light of the long-term effects of early life conditions on cognitive development and human capital accumulation noticed elsewhere. Our estimates suggest that expansions in public health infrastructure would be a cost-effective way of reducing the response of infant mortality to rainfall shocks in the Brazilian semiarid. 


\section{Introduction}

Arid and semiarid regions encompass 54\% of the developing world's agricultural area and one-third of its rural population. Close to 1 billion people today, among the poorest in the planet, live in regions characterized by recurrent moisture stress. A large fraction of this population has inadequate access to water supplies and improved sanitation facilities (World Bank (2008), United Nations Development Programme (2006)). ${ }^{1}$ For them, collecting water for consumption, hygiene, and agricultural production is a daily task that demands energy and resources. Lack of adequate access to water also increases the susceptibility to climatic shocks associated with fluctuations in rainfall. In a context of poverty and lack of access to insurance mechanisms, these shocks can have serious welfare consequences both in the short and in the long run. Notoriously, water scarcity can reduce agricultural production and nutrient intake, impacting health outcomes. In addition, it can directly lead to increased incidence of infectious diseases, such as diarrhoea, particularly affecting young children and pregnant women (World Health Organization (2010) and (2012)).

This paper analyzes the impact of rainfall fluctuations during the gestational period on health at birth. We concentrate on the semiarid region of Northeastern Brazil - the driest region in the country - to highlight the role of water scarcity as a determinant of early life health. This region has long been subject to harsh climatic conditions, with intermittent events of drought, water scarcity and food insecurity (see, for example, SUDENE (1981), Ab'Sáber (1999), and Áridas (1995)). We examine whether and how idiosyncratic shocks to rainfall during the time in utero affect a range of health outcomes at birth, including birth weight, number of weeks of gestation, and infant mortality (by cause of death, gender, season of birth, and time since birth). We also explore the specific channels linking variation in rainfall to health outcomes at birth. In our setting, there are two main potential connections in this relationship: (i) lower agricultural production and lower nutrient intake; and (ii) lack of safe drinkable water and higher incidence of infectious diseases.

This research has considerable data requirements. We make use of high frequency gridded information on precipitation and temperature to construct a municipality-by-month weather dataset. This dataset is then combined with birth and mortality registration records to create a municipality-by-month panel on weather conditions and birth outcomes. Our identification strategy relies on the hypothesis that temporary rainfall deviations from historical averages, conditional on municipality-by-month fixed-effects, are uncorrelated with other la-

\footnotetext{
${ }^{1}$ An estimated 900 million people in the world today live with inadequate access to water supplies and 2.7 billion live without improved sanitation facilities (World Health Organization (2010)).
} 
tent determinants of health during gestation. Under this assumption, we are able to identify the causal impact of rainfall variation on outcomes at birth.

Our results indicate that negative rainfall shocks are robustly correlated with higher infant mortality, lower birth weight, and shorter gestation periods. Mortality effects are concentrated on intestinal infections and malnutrition, and are greatly minimized when the local public health infrastructure is sufficiently developed. Conditional on income, the estimated impact of rainfall fluctuation decreases monotonically with municipality coverage of piped water and sanitation, loosing statistical significance when coverage of these public goods is high enough. At the same time, results do not seem to be associated with agricultural production, remaining virtually unchanged when we control for production per capita in the years surrounding birth. We also find that effects are stronger during the fetal period $\left(2^{\text {nd }}\right.$ trimester of gestation) and for children born during the dry season. Overall, our results seem to be capturing the effects of scarcity of drinkable water per se, and not reduced agricultural production, on birth outcomes. Apart from its own relevance, this evidence is also important in light of the long-term effects of early life conditions on cognitive development and human capital accumulation noticed elsewhere (Shenkin et al. (2004), Linnet et al. (2006), Mara (2003), Almond and Currie (2010), Glewwe and Miguel (2008), Currie (2009)).

A series of recent papers have addressed the relationship between environmental shocks and health and socioeconomic outcomes. Deschenes and Moretti (2009), for example, analyze the impact of temperature fluctuations on mortality in the US and Burgess et al. (2011) conduct a similar exercise for India. Deschenes et al. (2009) show, also for the US, that exposure to high temperatures during pregnancy leads to lower birth weight. In relation specifically to rainfall, there has been a growing body of research exploring different settings and potential channels. Maccini and Yang (2009) look at rural Indonesia and find long lasting impacts (health, education and labor market outcomes) of early-life rainfall fluctuations for women, with no noticeable effect for men. Positive deviations during the first year of life are associated with better outcomes during adulthood, while no significant effect is found for rainfall fluctuations before birth. Kudamatsu et al. (2010) use DHS data for various African countries to analyze the impact of rainfall fluctuations on infant mortality by malaria and malnutrition. They find that increased rainfall is associated with higher mortality by malaria in epidemic, but not in endemic areas, supposedly due to higher acquired immunity in the latter. When looking at malnutrition, they find non-significant impacts on the average, but highly non-monotonic heterogeneous effects. Their results suggest that, in arid areas, both increased rainfall and droughts are associated with higher infant mortality. Using as well 
DHS data for West Africa, Kim (2010) also finds no association on average between rainfall fluctuation around birth and infant mortality, but uncover a similarly puzzling positive relationship during the growing season. The author rationalizes this result by suggesting that positive rainfall shocks during the growing season increase the demand for labor in agriculture, reducing the time mothers spend with children and compromising breast-feeding. Skoufias et al. (2011) look at rural areas in Mexico and find that rainfall variations do not impact negatively household welfare as measured by consumption expenditure, but, similarly to the papers mentioned before, that positive rainfall shocks have a negative impact on child health. These authors suggest that the result is evidence of a pathway through the disease environment. Aguilar and Vicarelli (2011), looking again at Mexico, find that children born around years and regions affected by excessive rain caused by the El Niño phenomenon experience slower anthropometric growth and cognitive development. In their case, this effect seems to be driven by reduced household income as a results of losses in agricultural production. Finally, Burgess et al. (2011), despite focusing on the impact of temperature variations, present some borderline significant results on the positive impact of low incidence of rainfall on overall mortality, which seem to work through lower agricultural productivity and higher food prices.

Overall, the evidence on the effect of rainfall variation on health is largely mixed, with positive and negative impacts estimated in different settings, as well as non-significant results. This should come as no surprise, since it is not clear a priori whether positive variations in rainfall should be seen as beneficial or harmful events. As recognized by many authors, there are various potential channels linking variations in rainfall to health and socioeconomic outcomes. Within an usual range of variation, increases in rainfall may increase agricultural production and lower food prices, improving nutrition and health. But rainfall may also increase the incidence of infectious diseases for which the vector's reproduction cycle or the transmission mechanism trusts on the availability of water, such as malaria, schistosomiasis, and dengue fever. Rainfall may also directly increase the availability of safe drinkable water, reducing the incidence of infectious diseases and improving the absorption of nutrients. Finally, either too much or too little water (floods or droughts) may disrupt agricultural production and impact rural households' income and access to food.

The simultaneous operation of all these channels is likely to be responsible for the heterogeneous results obtained across the studies mentioned above, and also to be behind some puzzling non-monotonic effects estimated in specific cases. Our focus on the Brazilian semiarid helps solve this problem and renders positive rainfall variations into unequivocally beneficial 
events. $^{2}$ Differently from some of the papers above, who construct rainfall variables from aggregate measures of rainfall in different seasons, we use monthly information to construct rainfall variables for specific months before and after birth. Using municipality-by-month fixed effects, we guarantee that outcomes associated with a particular time of the year in a given municipality are accounted for, so that systematic differences across seasons and locations - and combinations of both - do not contaminate the estimated coefficients. As a result, we obtain clear-cut and robust evidence on the effect of rainfall variation during pregnancy on an expanded set of birth outcomes: birth weight, length of gestation, and mortality by cause of death. Finally, we are able to go one step further and link the results specifically to the availability of safe drinkable water and, as opposed to the previous literature, to rule out the most commonly considered channel through agricultural production. Despite not being explicitly considered in previous studies, water scarcity is extremely relevant to rural populations in the developing world and is likely to become an even more prevalent phenomenon with climate change (World Bank (2008), United Nations Development Programme (2006)).

The public health literature has long understood the mechanisms linking water scarcity to health outcomes. There are even estimates available of the likely impact of expansions in access to water and sanitation on the incidence of diarrhoeal diseases and child mortality. But these are based on the distribution of diseases across the globe and on a theoretical relationship between water and sanitation and health conditions (see, for example, World Health Organization (2010). There is no causal estimate available on the observed outcomes that can be unequivocally attributed to water scarcity. Similarly, there is no direct evidence on the quantitative role of water and sanitation infrastructure in minimizing the effects of climatic shocks in a real setting.

The main result from our benchmark specification indicates that a one standard deviation increase in rainfall - corresponding to a $31 \%$ increase from the average - leads to a reduction of 2.14 points in the infant mortality rate (or $7 \%$ of the sample average of 31.3 deaths per 1,000 births). The concrete meaning of this number can be grasped by considering a period subject to particularly negative shocks, such as the second half of 1998 when rainfall was roughly $50 \%$ below the historical average. The estimated coefficient implies that the infant mortality rate during this period was 3.5 points above the level observed in the semiarid in a typical year. Overall, susceptibility to rainfall conditions in the region would have historically led to an average infant mortality rate 3.8 points above what it would otherwise

\footnotetext{
${ }^{2}$ The Brazilian Northeast has no occurrence of malaria, which is concentrated in the Northern part of the country (Amazon).
} 
have been.

Our results also suggest that increased coverage of piped water and sanitation greatly reduces the response of infant mortality to rainfall fluctuations. For example, in a municipality with $20 \%$ coverage of piped water and sanitation, a variation in rainfall from the $90^{t h}$ to the $10^{\text {th }}$ percentile would lead to an increase of 6.3 points in the infant mortality rate. In a municipality with $100 \%$ coverage of sanitation and piped water, the response of infant mortality to a similar shock would be an increase of only 2.3 points (and not statistically significant). Improved access to water and sanitation would therefore lead to a reduction in the impact of the rainfall shock of 4 deaths per 1,000 births.

Using cost estimates from the Brazilian Ministry of Cities, we conduct a preliminary cost-benefit analysis of the expansion of sanitation and piped water coverage in the semiarid region. Our calculations indicate that relatively low values of a statistical life - at most US\$ 344,000 - would be enough to justify the expansion of piped water coverage to $100 \%$ of the households in the region. Sanitation is less cost-effective, requiring much higher values of a statistical life to justify universalization (in some scenarios, above US\$ 1 million). Still, even considering only the impact on infant mortality, universalization of both piped water and sanitation combined seems to be effective from a cost-benefit perspective.

The remainder of the paper is organized as follows. Section 2 describes our empirical setting and provides a conceptual discussion of the links between water scarcity and health. Section 3 presents the data and descriptive statistics. Section 4 details our empirical strategy. Section 5 presents and analyzes the results. Finally, section 6 concludes the paper.

\section{Background}

\subsection{The Brazilian Semiarid Northeast}

The Brazilian Northeast comprises 9 states and 1,800 municipalities. Its semiarid region is located mostly inland and includes 1,048 municipalities. We follow the official definition of the semiarid region given by the Brazilian Ministry of National Integration (ordinance \#89/2005). According to this definition, a municipality is part of the semiarid region if it satisfies one of three climatic characteristics (SUDENE (2008)): (i) it is within the boundaries of isohyets below $800 \mathrm{~mm}$, i.e., the lines on a map joining points of historical average precipitation below $800 \mathrm{~mm}$ (yearly precipitation records from 1961 to 1990); (ii) it has average Thornthwaite Index below 0.50 (this indicator combines humidity and aridity indices to determine an area's moisture regime); and (iii) it has an index of risk of drought above 
$60 \%$ (the index is defined as the share of days under hydric deficit, which accounts for daily precipitation and evapotranspiration, also calculated with data from 1961 to 1990).

The semiarid Northeast is the poorest region in Brazil. During our sample period (1996 to 2008), roughly $80 \%$ of children are below the poverty line and infant mortality reaches 31 per 1,000 births, as opposed to the Brazilian averages of, respectively, 25\% and close to 15 per 1,000 births. Around $53 \%$ of its 20 million dwellers live in rural areas, compared to $19 \%$ for the country as a whole. Municipalities are typically small, with population median around 12 thousand inhabitants. ${ }^{3}$ The semiarid economy is largely based on extensive forms of subsistence agriculture and cattle raising, with very low productivity and great dependence on weather fluctuations (Ab’Sáber (1999), Áridas (1995), SUDENE (1981), Áridas (1995), Cirilo (2008)).

The region is also the driest in Brazil. Figure 1 portrays yearly precipitation between 1938 and 2008 for the semiarid region of the Northeast and for the rest of Brazil (the data are discussed in the next section). Average historical precipitation in the semiarid is slightly below $750 \mathrm{~mm}$, corresponding to less than half the average for the rest of the country (around $1700 \mathrm{~mm}$ ). The figure also shows that events of rainfall scarcity have been recurrent throughout the past decades. This is consistent with existing historical records: various authors document severe droughts in the early 1950s, 1958, 1970, early 1980s, early 1990s, and 1998 (SUDENE (1981), Campos (1994), Villa (2000)). All these episodes can be seen in Figure 1.

The pattern of weather fluctuation within years is shown in Figure 2. There are two marked seasons: the rainy season (first semester), with precipitation levels particularly high between February and April, when sowing typically takes place; and the dry season (second semester), with monthly precipitation levels often close to zero. Temperatures, in contrast, vary little, with monthly averages always between $22^{\circ} \mathrm{C}$ and $26^{\circ} \mathrm{C}$. Episodes of drought typically occur when precipitation during the first semester is unexpectedly low and irregular. Coupled with the geographic characteristics of the region, these episodes can seriously jeopardize water supplies.

The semiarid has a very poor network of rivers, with weak runoff volumes. This is a result of the variability of rain over time and of the composition of the soil, which is mostly shallow and formed from crystalline rocks. This formation leads to little accumulation of water and low exchange between rivers and adjacent soil, resulting in a dense network of

\footnotetext{
${ }^{3}$ Mortality data from Datasus and socioeconomic information from the 2000 Census. Child poverty rate is the share of individuals aged between 0 and 14 living in households with per capita income below the poverty line (defined as $\mathrm{R} \$ 75.50$, or $1 / 2$ the August 2000 minimum wage).
} 
intermittent rivers. In addition, groundwater wells have typically low flow and provide water of high salinity (Cirilo (2008)). Most of the water used by households is obtained from dams and rainwater ponds, which vary in capacity from a couple of state sponsored reservoirs of billions of cubic meters $\left(\mathrm{m}^{3}\right)$, to several thousand smaller private reservoirs of up to 200,000 $\mathrm{m}^{3}$ (Rebouças (1997)).

These dams and ponds accumulate water during the rainy season and are used throughout the year. But, in reality, there is severe underuse during the rainy season because of lack of planning and fear of future water scarcity. As an outcome, water is lost due to evaporation and, in the dry season, the remaining water display high levels of salinity and low quality for consumption. Potential evaporation in the region reaches 2,500 $\mathrm{mm}$ per year (Cirilo (2008)), with the hydrologic efficiency of the water reserves estimated to be roughly $1 / 5$ of their volume (Rebouças (1997)). As Rebouças (1997) notices, some ponds reach salinity levels higher than those registered in the Dead Sea. When rainfall during the rainy season is low, this problem is intensified and scarcity of high quality water becomes a major issue. To aggravate this scenario, local bodies of water are still the main destination of sewage. Primitive forms of agriculture and cattle raising - also concentrated around water - further contribute to the depletion of the soil, contamination, and reduction of available reserves (Cirilo (2008)).

We believe that our focus on a semiarid region presents a series of advantages in relation to the previous work on rainfall fluctuations. First, the semiarid region turns positive rainfall shocks into unequivocally beneficial events, avoiding the non-monotonic effects that are present in the literature. ${ }^{4}$ This allows us to look at the effect of water scarcity on birth outcomes. Second, arid and semiarid regions cover one third of the earth's land surface. According to the World Bank's World Development Report 2008, one-third of the developing world's rural population, corresponding to 820 million people among the poorest in the planet, live in these areas (World Bank (2008)). With changing climate, arid and semiarid regions are expected to become even more prevalent (United Nations Development Programme (2006)). In the Brazilian Northeast itself, the El Niño phenomenon has already increased the severity of droughts, and rising temperatures are expected to further enhance evaporation and reduce water availability (Cirilo (2008)).

\footnotetext{
${ }^{4}$ Figure 1 shows that yearly precipitation in the semiarid region of Northeastern Brazil did not reach the historical average for the rest of the country at any point in time. In the 70-year interval portrayed, this did not happen even in the extreme outlier for positive rainfall shocks, which was the year of 1986.
} 


\section{$2.2 \quad$ Water and Health}

Water is life, but it is also a means of transmission of diseases and transportation of contaminants. Drinking water can deliver pathogens and toxic substances, hazards that are greatly increased in the absence of sanitation and waste management services. Inadequate water resources management can also affect water ecology leading to the proliferation of vectors of diseases, such as malaria, schistosomiasis, and dengue fever (Fewtrell et al. (2007)). Finally, either too much or too little water can disrupt agricultural production, reducing food availability and increasing malnutrition (United Nations Development Programme (2006)).

We focus here on water scarcity. In this context, two of the channels described above gain particular relevance. First, lack of water may directly impact households dependent on agriculture through reduced nutrient intake due to lower production and less varied diets. This leads to malnutrition and micronutrient deficiency, potentially including deficits of vitamins A, B1, B3, and C, and iron (World Health Organization (2012)). Second, lack of adequate water supply combined with poor sanitation increases the risk of infectious diseases, most importantly diarrhoea and respiratory infections. Indirectly, through reduced capacity to absorb nutrients, diarrhoea can also lead to increased malnutrition (World Health Organization (2012)).

The impact of water scarcity on agricultural production is straightforward, but that on infectious diseases may seem less obvious. The key connection is the fact that, in arid regions in developing countries, water quantity means water quality. Increases in water quantity increase the use of water for personal hygiene, reduce the travel time to collect water, reduce the need to store water in unsanitary conditions, and increase the quality of the traditional sources of water. In contexts of water scarcity, these tend to generate health benefits that far outweigh those that could be obtained from improvements in water quality, for a given quantity (Sobsey (2002), Mara (2003), Pond et al. (2011)).

In combination with poor sanitation, inadequate access to water is the leading risk factor for diarrhoeal diseases. Diarrhoea is caused mainly by pathogens that are ingested from unsafe water, contaminated food or hands. It is alone the second most important factor in the global burden of diseases (World Health Organization (2010)). For children, its estimated burden is greater than that of HIV, malaria, and tuberculosis combined, with a total of 1.8 million deaths each year. In addition, roughly $50 \%$ of childhood deaths attributed to malnutrition are thought to be associated with severe repeated diarrhoea (and other intestinal infections) and the resulting incapacity to absorb nutrients (United Nations Development

Programme (2006), World Health Organization (2010)). Malnutrition, in turn, also increases 
the susceptibility to and severity of new infections, reinforcing a vicious cycle (see discussion in Fewtrell et al. (2007)).

Pregnant women and their fetuses, together with young children and the elderly, are particularly vulnerable to the health problems associated with water scarcity (Pond et al. (2011)). Biological demands for water and nutrients are greatly enhanced during pregnancy. With gestation, body water increases by 7 to 8 liters, which are roughly shared between the maternal and fetal placental compartments (Barron (1987)). Increased basal metabolism and tissue synthesis also raise the demand for nutrients. Requirements of proteins, fats, various vitamins (including A, B1, B3, and C), iron, iodine, and zinc are increased. Deficient intake of some of these may lead to birth defects, low birth weight, obstetric complications, premature birth, and higher perinatal mortality (Steegers-Theunissen (1995)). Water deprivation by itself may also lead to dehydration-anorexia, resulting in an additional channel of nutrient stress (Ross and Desai (2005)).

Generally, fetal growth, length of the gestation period, and birth weight are thought to be associated with offsprings' improved health outcomes. Fetal growth is mainly regulated by nutrition. Marginal changes in maternal nutrition do not necessarily lead to changes in fetal nutrition, as the fetus lies at the end of a long supply line (Bloomfield and Harding (1998)). But significant maternal malnutrition implies that the fetal substrate may not meet fetal demands, leading to a deceleration in the fetal growth trajectory (Bloomfield et al. (2006)). Low maternal body-mass index and intrauterine growth restrictions are considered risk factors for neonatal conditions. According to the medical literature, poor fetal growth is rarely a direct cause of death, but rather can contribute indirectly to neonatal deaths, particularly those due to birth asphyxia and infections (sepsis, pneumonia, and diarrhoea), which together are estimated to account for about $60 \%$ of neonatal deaths in the world (Black et al. (2008)).

The relevance of the issue is enhanced by the fact that fetal growth trajectory and birth weight may have long-term effects. The fetal origins hypothesis argues that in utero environmental influences can have permanent impacts through the underdevelopment of organs and predisposition to chronic diseases during adulthood (Barker (1998a), Barker (1998b), Ross and Desai (2005)). Fetal malnutrition in critical periods of rapid cell division is identified as a key factor in this relationship. Protein deficits, for example, have been associated with delayed brain development, as discussed by Morgane et al. (1993). In fact, while causal empirical evidence is limited, many studies in medical sciences and psychology suggest that low birth weight and other early life insults may lead to impaired cognitive 
development (Shenkin et al. (2004), Linnet et al. (2006), Mara (2003)). A large body of literature has also documented that schooling may be directly affected by in utero and early childhood conditions (Almond and Currie (2010), Glewwe and Miguel (2008), Currie (2009)).

In this paper, we focus on the effects of rainfall fluctuations during the gestational period on health outcomes at birth and during the first year of life. Since we concentrate our analysis on the Brazilian semiarid, we see variations in rainfall as shocks to water scarcity. In this context, increased rainfall is potentially related to increased agricultural production and availability of food and nutrients (Suliano et al. (2009), Maccini and Yang (2009)), ${ }^{5}$ and also to increased access to safe drinkable water and reduced incidence of infectious diseases (Parry et al. (2007), Luna (2007), Kudamatsu et al. (2010)).

\section{Data}

\subsection{Climate Data}

We construct historical series of precipitation and temperature using the Terrestrial Air Temperature and Precipitation: 1900-2008 Gridded Monthly Time Series, Version 1.02 (Matsuura and Willmott (2009)). This dataset provides worldwide monthly temperature and precipitation estimates at the $0.5 \times 0.5$ degree level $(0.5$ degree corresponds roughly to 56 kilometers). Estimates for each node in this grid are obtained from calculations based on an average of 20 nearby weather stations. We first locate each municipality in our sample within a square defined by the four closest nodes. Henceforth, we call this square associated with a given municipality its grid. Following, we construct monthly precipitation and temperature series for each municipality as the weighted average of the estimates associated with the four nodes of its grid, where the weights are the linear distances from the municipality's centroid to each node.

We construct two variables measuring rainfall fluctuation during an individual's gestation period. The first variable is defined by the following equation

$$
R_{m \tau}=\ln \left(\sum_{t=\tau-11}^{\tau} r_{m t}\right)-\ln \left(\bar{r}_{m}\right),
$$

where $r_{m t}$ indicates the monthly rainfall in municipality $m$ and month $t, \bar{r}_{m}$ is the average historical yearly rainfall in municipality $m$, and $\tau$ indicates an individual's month of birth.

\footnotetext{
${ }^{5}$ For example, Suliano et al. (2009) estimated that a $1 \%$ increase in yearly precipitation is associated with a $0.4 \%$ increase in agricultural production in the Northeastern state of Ceará.
} 
Thus, $R_{m \tau}$ is defined as the deviation between the natural logarithm of the total rainfall in the 12 months prior to the individual's birth and the natural logarithm of the average yearly rainfall in municipality $m$. We consider 12 months prior to birth, instead of 9 months, because evidence suggests that the nutritional status of the mother immediately before conception is also important in determining birth outcomes (see, for example, discussion and references in Kudamatsu et al. (2010)). The historical average $\bar{r}_{m}$ is calculated for each municipality over the period from 1938 to 2008. The variable $R_{m \tau}$ can be approximately interpreted as the percentage deviation from mean rainfall. For instance, a value of 0.01 means that rainfall over the 12 months prior to an individual's birth was roughly $1 \%$ above average. Maccini and Yang (2009) use a similar variable, but they construct rainfall fluctuations from data aggregated into seasons (6 month-periods), leading to measurement error in the rainfall attributed to pre and post-natal periods. The way our variable is constructed allows for a more precise measurement of the timing of rainfall. In order to conduct some robustness exercises and to control for other dimensions of climate, we also construct variables measuring temperature (average in the 12 months prior to birth) and rainfall in other periods (12 months before and after birth).

The second variable is a dummy designed to capture extreme events, similar to that used by Kudamatsu et al. (2010), though - as Maccini and Yang (2009) - they also use rainfall aggregated into seasons. We define an episode of drought in the following way

$$
D_{m \tau}=1 \text { if } \sum_{t=-11}^{\tau} r_{m t}<\left(\bar{r}_{m}-r_{m}^{S D}\right), \text { and } 0 \text { otherwise, }
$$

where $r_{m}^{S D}$ is the historical yearly standard deviation of rainfall for municipality $m$ (calculated over the 1938-2008 period). In words, $D_{m \tau}=1$ indicates that rainfall over the 12 months prior to an individual's birth was more than one standard deviation below the historical average for municipality $m$.

Figure 3 presents the yearly averages for the two variables defined above. The figure shows that the incidence of rainfall shocks in the semiarid varies significantly in the timeseries and in the cross-section. Panel A portrays the rainfall log-deviation, which has a standard deviation of 0.31. Panel B presents the time series for the drought variable, which highlights how the severity of shocks varies geographically within a given month. Episodes of drought occur, on average, in $14 \%$ of the municipalities in the sample. Still, there are periods with pervasive droughts hitting almost $100 \%$ of the municipalities and periods with no municipality experiencing a drought. 


\section{$3.2 \quad$ Health Outcomes}

We construct a dataset on health at birth and infant mortality combining microdata from the Brazilian National System of Information on Birth Records (Datasus/SINASC) and the Brazilian National System of Mortality Records (Datasus/SIM). The first database records every registered birth in Brazil - around 4.7 million in the semiarid region alone from 1996 to 2008 - and provides information on, among other things, birth weight and length of gestation. The database also provides the exact date of birth, the municipality of birth, and the municipality of residence of the mother. This information allows us to construct a municipality-by-month of birth panel over the 1996-2008 period containing information on number of births, average birth weight, and average length of the gestational period. The municipality of reference in the panel is the municipality where the mother lives, so that in principle we are able to capture the shock that the fetus was subject to during the gestational period. This is important because municipality of birth may be related to the availability of medical facilities in a given area, as when mothers travel across municipalities to give birth in a hospital.

The National System of Mortality Records gathers information on every death officially registered in Brazil. It contains data on cause of death, date of birth, municipality of birth, and municipality of residence. We select all deaths of individuals up to one year of age born in the semiarid region of the Northeast between 1996 and 2008 (making a total of 140,102 infant deaths). We then build a municipality-by-month of birth panel for the 1996-2008 period containing information on number of infant deaths (total and by cause of death).

These panels on births and infant mortality are merged by municipality and month of birth. The consolidated dataset allows us to calculate infant mortality rates by municipality and month of birth. Finally, we combine this dataset with our weather data by linking month and municipality of birth with municipality-specific measures of rainfall over the 12 months prior to an individuals' birth. Table 1 presents summary statistics for this dataset. Average number of births per month is 28.9 (the median, not shown in the table, is only 14). Average birth weight is 3.3 kilograms and $94 \%$ of pregnancies last 37 weeks or more. The average number of infant deaths per month is 0.84 , with infant mortality rates of 31.3 per 1,000 births. In this sample, the average incidence of rainfall in a typical 12-month period is 800 $\mathrm{mm}$, with an average rainfall log-deviation of 0.022 and $9.7 \%$ of observations corresponding to droughts. 


\subsection{Other Data}

We make use of additional information to try to uncover the channels behind the relationship between rainfall fluctuations and health at birth. We collect municipality level data on: (i) percentage of households with access to piped water, percentage of households with access to sewerage connected to the public sanitation system, and average household income per capita, all from the 2000 Brazilian Census; and (ii) yearly agricultural production per capita from the Municipal Agricultural Surveys (PAM), conducted by the Brazilian Census Bureau (IBGE).

\section{Empirical Strategy}

Our sample is composed of municipalities in the semiarid region of the Northeast of Brazil. The analysis of the health impacts of rainfall fluctuations during the gestational period is based on a municipality-by-month of birth panel. Our benchmark specification is the following

$$
H_{m y t}=\alpha+\beta R_{m y t}+\phi_{m t}+\lambda_{y}+\varphi \operatorname{Trend}_{g y t}+\pi T_{m y t}+\epsilon_{m y t},
$$

where $H_{m y t}$ is a health outcome (municipality average) for children born in municipality $m$, on year $y$ and month $t$; $R_{m y t}$ is our rainfall variable (either log-deviation of rainfall in the 12 months prior to birth or a dummy indicating a drought in the same period); $\phi_{m t}$ is a fixed-effect for municipality $m$ and calendar month $t$ (with $t=1,2, \ldots, 12$ ); $\lambda_{y}$ is a year fixed-effect; $T_{m y t}$ is the average temperature in the municipality in the same 12-month period before birth; Trend $_{g y t}$ is a grid-specific linear time trend; and $\epsilon_{m y t}$ is a random error term. Our key dependent variable $\left(H_{m y t}\right)$ is infant mortality, but we also look at birth weight, length of gestation, infant mortality by cause of death, number of births, and sex-ratio at birth.

The main concern in this specification is the possibility of confounding omitted factors correlated both with rainfall and health at birth. This is clearly the case in the cross-section, since places with harsher climate tend to have worse socioeconomic conditions. But notice that we have 12 monthly fixed-effects in each of the 1,048 municipalities, resulting in over 12,500 additive independent variables. They control for any effect associated with climatic or socioeconomic conditions typical of specific months of the year in a given municipality. So recurrent level effects - possibly associated with wet and dry seasons, harvests, availability 
of food, etc - are all washed away in the municipality-by-month fixed-effects.

Year fixed-effects, in turn, capture aggregate shocks impacting the entire semiarid region. Grid-specific time trends control for potential long-run differences in climatic dynamics and other socioeconomic characteristics across regions within a state. As mentioned before, we call grid the square defined by the four nodes closest to a municipality centroid (from the $0.5 \times 0.5$ degree weather dataset). This linear time trend is common to all municipalities included in a given grid. Finally, the control for temperature accounts for other climatic variations possibly correlated with rainfall also taking place at the municipality level.

Our identification relies on the assumption that a temporary rainfall deviation from its historical average - conditional on a long-term trend and temperature variations - is uncorrelated with any latent determinant of health at birth. Under this assumption, we are able to identify the causal impact of rainfall shocks on early life outcomes. It is difficult to think of plausible stories of endogeneity or omitted factors when considering this type of temporary variation in rainfall, conditional on all our independent variables. Still, there are multiple potential channels through which rainfall may affect health at birth. We analyze the role of the main potential channels likely to be at work in our setting.

In all specifications, we use robust standard errors clustered by grid, the level at which we measure rainfall and temperature. Also, since mortality and other birth related variables are measured with less precision when there are fewer births, our benchmark specification weights observations by the average number of births per month. Lastly, since large urban centers may have different characteristics and may end up greatly influencing the results in a weighted regression setting, we trimmer from the sample municipalities in the top $1 \%$ of the distribution of number of births (above 289 births per month).

In trying to understand the results from our benchmark specification and to shed light on the channels linking variations in rainfall to birth outcomes, we look at the heterogeneity of effects across various margins. We analyze boys and girls separately; look at rainfall variation in different moments of the gestational period and at different seasons of the year; analyze impacts over various mortality horizons; and look at heterogeneous responses by municipality coverage of treated water, sanitation, and level of income per capita. In some robustness exercises, we also control for local agricultural production, in order to analyze whether rainfall impacts are working through food availability.

A potential problem pervading our analysis concerns fetus selection due to adverse weather conditions. This type of caveat is recurrently mentioned in the birth weight literature (see, for example, Currie (2009), p.106). The problem is that only surviving fetuses 
are recorded in our dataset. Hence, shocks that tend to cull weak fetuses before birth or reduce women's fertility due to health or behavioral responses may lead the population of surviving newborns to be stronger than it would otherwise have been. As Currie (2009) argues, fetal selection suggests that estimated coefficients may understate the true negative effects of health insults. ${ }^{6}$

Figure 4 shows the pattern of monthly averages for number of births and infant mortality in our dataset, for periods with and without droughts (defined according to the variable discussed before). Not surprisingly, infant mortality tends to be higher for births in periods with droughts, and particularly so between July and December. Interestingly, the seasonal pattern of mortality is much more pronounced in periods with drought. Analogous but inverted patterns are observed for number of births. The number of births tends to be lower in periods with drought, and this difference is particularly large in the $2^{\text {nd }}$ half of the year. In our dataset, periods with higher mortality are periods with fewer births, so that the effect of a drought on surviving children seems to be larger than the potential selection effect before birth. Still, the same issue discussed by Currie (2009) is likely to be at work, meaning that the true effect of rainfall on birth outcomes is likely to be stronger than that estimated here (on the assumption that part of the negative impact is reflected on miscarriages). Selection through women's fertility is also possible, given that unhealthy women are less likely to become pregnant, though some authors have argued that these effects should be quantitatively small (see Frisch (1978) and following discussion by Bongaarts (1980)).

Finally, in our setting, selection from conscious choices of parents, through delayed pregnancy in anticipation of negative rainfall shocks, does not seem plausible. Given that we explore transitory variations in rainfall, this would require an extremely sophisticated forecast of the likelihood of rainfall over several months following conception. This is not realistic. In any case, selection at birth is likely to bias estimated coefficients toward positive values, reducing the estimated impact of rainfall variation on birth outcomes.

\footnotetext{
${ }^{6}$ This survivor-bias has long worried the empirical research on the health and welfare (Gorgens et al. (2011)). For example, Friedman (1982) suggests this type of bias as a possible explanation for the increased height of slaves in Trinidad. Bozzoli et al. (2009) find that population height increases with mortality rate for countries where infant mortality exceeds a threshold level. And Gorgens et al. (2011) use data from the 1959-1961 Great Chinese Famine and find that taller children were more likely to survive the famine. They also find no apparent pattern of stunting amongst famine cohorts. However, when controlling for selection, the authors estimate that children who survived the famine grew up to be shorter than they would otherwise have been.
} 


\section{Results}

\subsection{Benchmark Specification}

Table 2 presents the results from our benchmark specification for the effect of rainfall fluctuations on infant mortality. We start from column 1 with the lightest specification and progressively introduce changes to the estimating equation, until we arrive at our full specification in column 4. The first column includes municipality-by-month fixed-effects, year of birth fixed-effects, and grid-specific linear time trends. The second column excludes municipalities in the top percentile of number of births (above 289), since these are likely to be large urban centers where the mechanisms we explore should not be so relevant. In column 3 , we weight observations by the average number of births, to account for the correlation between the variance of mortality rates and number of births. Following, in column 4, we control for the average temperature in the 12 months prior to birth, to make sure that the effect we are capturing is not due to broader climatic changes. Finally, in column 5, we conduct our first and probably most important robustness exercise by analyzing whether rainfall variation during pregnancy is not in reality capturing the effect of rainfall in other periods (before conception and after birth). In order to tackle this issue, we control for rainfall deviations in the period comprising 12 to 24 months before birth and in the first year of life. Panel A presents this sequence of columns when we use the log of rainfall variation as our independent variable, and Panel B presents analogous results when we use our measure of drought.

Panel A shows that there is a negative and statistically significant correlation between rainfall and child mortality. Increases in rainfall during the gestational period are associated with reduced mortality during the first year of life. Results remain virtually unchanged when we move from column 1 to column 2, indicating that municipalities in the top 1\% of the number of births are playing no role in generating the observed correlation. In column 3 , when we weight regressions by the average number of births, the coefficient increases by more than $50 \%$ in magnitude remaining strongly significant. This should be expected given that the variance of mortality is higher for smaller municipalities and mortality is bounded from below by zero. In column 4, when we control for temperature during pregnancy, results remain almost identical, indicating that the effect we are capturing comes particularly from rainfall rather than from broader climatic conditions.

As mentioned before, column 5 in Table 2 introduces our first robustness test. One main potential concern in this initial specification is that rainfall variation during pregnancy is 
correlated with rainfall variation in other periods - before conception or after birth - and it is indeed rainfall in these other periods that affects health outcomes. Maternal nutrition before conception might determine the quality of fertilized eggs, having an impact on the formation of the fetus, while rainfall during the first year of life might directly affect children's nutrition and disease environment. Medical studies of the relationship between maternal health and birth weight suggest that the period before and around conception is important for the fetus growth trajectory. Birth weight of a newborn is reported to be correlated with the prepregnancy weight of the mother (as reviewed in Bloomfield et al. (2006)). Early postnatal conditions can also be critical once infant health is vulnerable to shortages of potable water and to the disease environment after birth. On the other hand, as argued by Kudamatsu et al. (2010), breast-feeding is known to lower mortality risk during that period. As long as it is not very severe, maternal malnutrition has little impact on the volume and composition of breast milk (Brown and Dewey (1992), cited in Kudamatsu et al. (2010), p.19). To address these concerns, the last column in Table 2 includes as additional controls the log deviation of rainfall in the interval of 12 to 24 months before birth and in the first year of life. The added variables turn out to be both negative, but neither is statistically significant. The result is identical if we include each of these variables separately, one at time. In addition, when they are included in the regression, the coefficient on rainfall during the gestational period increases in magnitude and remains statistically significant. It seems to be indeed the amount of rainfall during the gestational period that is affecting infant mortality, rather than rainfall in other moments in time. In Panel B, we present analogous results using drought as the independent variable. The qualitative patterns are similar - indicating in this case that droughts are associated with increased infant mortality - though a little less precisely estimated in the first two columns. ${ }^{7}$

Overall, irrespective of how we measure rainfall fluctuations, we detect a negative and statistically significant impact of increased water availability on infant mortality. For the

\footnotetext{
${ }^{7}$ The dataset with detailed birth information started being compiled in the early 1990s. The first years of the dataset contain a lot of missing information. For some states, missing data appears up until 1996 and 1997. Still, we choose to include 1996 and 1997 in the dataset because 1998 represents the last year of a major drought episode, so the presence of a baseline period with roughly normal conditions generates relevant variation to identify the parameters of interest. In the Appendix Table A.1, we present results when we restrict the sample in different ways: excluding 1996 and 1997, one at a time and then at the same time; excluding states with a high number of missing observations; excluding municipalities with a missing observation in 1996; and excluding municipalities with a missing observations at any point in the sample period. The last column in the table presents results using number of infant deaths, instead of mortality rate, as the dependent variable. All estimated coefficients are negative and statistically significant, some being quantitatively similar to those presented in Table 2 and others a bit different in magnitude.
} 
interested reader, Appendix Table A.2 presents analogous results when we use categorical variables indicating different levels of rainfall (the omitted category is above $1200 \mathrm{~mm}$ ). Column 1 in that table indicates approximately monotonic increases in mortality as rainfall falls from $1000 \mathrm{~mm}$ down to values below $400 \mathrm{~mm}$. Given that most of the variation in rainfall in the sample is concentrated between $500 \mathrm{~mm}$ and $1000 \mathrm{~mm}$, we stick to the $\log$ deviation of rainfall as our preferred independent variable. It implicitly assumes that positive and negative rainfall shocks around the mean have symmetric effects.

Column 4 from Table 2 is our preferred specification and is the one we use in the remainder of the paper. The magnitude of the coefficient on the log of rainfall deviation is also quantitatively important. A $31 \%$ - or one standard deviation - increase in rainfall leads to a reduction of 2.14 in the infant mortality rate (or $7 \%$ of the mean). This result supports the view that variations in infant mortality in the semiarid region are strongly affected by rainfall fluctuations.

In Table 3, we further explore the health consequences of rainfall variation by looking at two additional birth outcomes (birth weight and length of gestation) and infant mortality by cause of death. We keep the specification from column 4 in Table 2 in all regressions. Our variable measuring the length of gestation is the fraction of births in a municipality in a given month that reached at least 37 weeks. Regarding infant mortality by cause of death, we look at the main drivers of early mortality: intestinal infections, malnutrition, respiratory infections, perinatal period conditions, congenital diseases, and non-reported causes. Together, these causes account for more than $97 \%$ of infant deaths in the sample. Finally, Table 3 also looks at number of births and sex ratio at birth, to shed further light on the potential selection that may be at work in our setting.

The first two columns show that increased water availability, in addition to reducing child mortality, increases birth weight and the probability of full-term pregnancies, though the effects are quantitatively very small. A $31 \%$ increase in rainfall is associated with an increase of 1.9 grams in birth weight (or $0.06 \%$ of the mean) and 0.6 percentage points in the fraction of full-term pregnancies (or $0.63 \%$ of the mean). It is somewhat puzzling that the estimated impacts are quantitatively so small, but that, nevertheless, the model is able to statistically detect them. This pattern has occurred before in the literature: Deschenes et al. (2009), for example, found very small quantitative effects of temperature variations on birth weight for the case of the US.

In terms of cause of death, significant effects are concentrated on three main conditions: intestinal infections, malnutrition, and non-reported causes. The estimated impact on these 
three causes of death add up to roughly the total mortality effect estimated in Table 2, therefore exhausting the impact of rainfall variation. There is also a borderline significant impact on respiratory infections, but the magnitude of the coefficient is considerably smaller. This result is particularly important because, as discussed in section 2.2, intestinal infections (mainly diarrhoea), malnutrition, and respiratory infections are precisely the types of conditions that should be affected by water availability (World Health Organization (2012)). Though the coefficient for intestinal infections is considerably larger, indicating a potentially important role for reduced access to clean water, it is also possible that part of the effect estimated for malnutrition is due to lower agricultural production and reduced food availability. In addition, since reporting of cause of death is deficient in some of the poor areas in our sample, the reduction in mortality by non-reported causes probably reflects further reductions in the two main causes of death identified before. If we redistributed the coefficient for non-reported causes proportionally to intestinal infections and malnutrition, the coefficient on the former would increase in magnitude to -5.5 and that on the latter to -1.8 . Overall, results are remarkably consistent with what should be expected from the effect of water scarcity in a semiarid environment.

The last two columns in Table 3 dig a little deeper in the selection problem. Column 9 shows that rainfall variation also tends to be associated with number of births (see also column 2 in Appendix Table A.1 for the same specification using categorical variables for different amounts of rainfall). Positive rainfall shocks are followed by a mild increase in the number of births, with no change in sex-ratio at birth (see column 10). The typical concern with selection at birth is that fewer births mean that individuals being born are stronger and better fit. Here, when considering shocks that affect health during the gestational period, we observe higher selection (lower number of births) precisely when birth outcomes are worse (higher mortality, lower birth weight, and shorter gestations). As mentioned before, it is extremely unlikely that parents are actively making fertility choices in anticipation of rainfall fluctuations. Therefore, number of births is probably just another dimension of health impacts from rainfall fluctuations, with water scarcity being associated with higher probability of miscarriages and lower probability of conception. It is still true that, with negative rainfall shocks and lower number of births, the births that are materialized are of better quality than those that are not. But, if anything, this selection tends to work against our results, since it generates a positive correlation between selection before birth and health outcomes at birth. The important point is that, when talking about such extreme shocks in the gestational period, selection seems to be relatively unimportant vis-à-vis the overall effect 
of the shock itself on surviving children. Negative rainfall shocks that reduce the number of births and increase mortality also worsen the health of those who survive. This was already apparent in Figure 4, but reveals itself again in Table 3.

\subsection{Gender Heterogeneity}

Table 4 explores the gender specificity of the results from Tables 2 and 3. We run the complete specification for boys and girls separately, looking at infant mortality, birth weight, length of gestation, mortality by cause of death, and number of births. To save on space, in the remainder of the paper we present results only for the log of rainfall deviation as independent variable. Qualitatively, the results for boys and girls separately replicate the patterns found before. Most interestingly, the coefficients for the birth outcomes for girls are always larger than those for boys, while the coefficient for number of births is larger for boys. Though these differences are statistically significant only in a few cases, this pattern is present in all columns in Table 4. It seems to be the case that health outcomes for girls are more responsive to rainfall variations in the gestational period than those for boys. In some cases - such as birth weight - this difference is substantial, while in others - such as gestational length or mortality by intestinal infections - it is less relevant.

It does not seem plausible that gender bias on the part of parents could account for these results, given that we are exploring shocks during the gestational period in very poor areas. In most cases it is even unlikely that the gender of the child is known before birth. In addition, gender bias at early ages is not considered a serious problem in Brazil. On face value, the qualititative results suggest that, before birth, boys are more fragile than girls. If this is the case, the impact of rainfall variation on number of boys being born would be greater than that on number of girls. And a higher number of girls surviving gestation could mean weaker girls being born. Though this logic is consistent with the qualitative results from Table 4, it is difficult to reconcile with the absence of an effect on sex ratio at birth in Table 3 and with the small quantitative effect on number of births.

Experimental research on medical sciences has detected gender specific effects of simulated water and famine conditions during pregnancy, even though the mechanism behind these results is not entirely understood (Ross and Desai (2005)). Maccini and Yang (2009) have also found gender specific long term effects, but they looked at rainfall during the first year of life and found no effect at all for males. Put together, this evidence suggests that gender heterogeneity in environmental shocks is probably the result of a combination of biological and social factors. In our setting, the biological dimension is likely to be the main 
driver, but further research on the topic is needed to clarify these relationships. Given our focus, this effort is beyond the scope of this paper.

\section{$5.3 \quad$ Timing}

Another important aspect of the effect of water scarcity on birth outcomes is the specific timing of the impacts. The question of timing has at least three relevant dimensions: (i) the moment of water scarcity during the gestational period; (ii) the moment of water scarcity during the calendar year; and (iii) the moment after birth when the effect of water scarcity is felt. In addition to being interesting and relevant on their own, these dimensions of timing may also shed light on the channels linking water scarcity to birth outcomes.

In Table 5, we explore the impact of variation in rainfall at different moments of the gestational period and of the calendar year. We focus on infant mortality as the dependent variable. In the first column, we run the same specification from column 4 in Table 2 , but break down the log of rainfall deviation into variables indicating different trimesters of gestation. These can be roughly classified as: before conception (one trimester before the beginning of pregnancy), embryogenesis (first trimester), fetal development (second trimester), and perinatal period (third trimester). In the second and third columns, we look only at children born during the rainy season (from January to June). We first look at the overall impact of rainfall deviation during pregnancy for these children, and then look at the effect by trimester of gestation. Finally, in columns 4 and 5, we repeat these exercises for children born during the dry season (from July to December).

Column 1 shows that, when looking at all births, significant impacts appear only in the first and second trimesters of gestation, corresponding approximately to the periods of embryonic formation and fetal development. We estimate much smaller and non-significant coefficients for the last trimester of gestation and for the period before conception. When we further break down the analysis by rainy and dry seasons, an additional striking result becomes apparent. Comparing columns 2 and 4, one can see that the effect of rainfall variation on infant mortality is much stronger for children born during the dry season. For the case of the rainy season, the estimated coefficient is -3.2 and imprecisely estimated, while for the dry season it is -10.9 and statistically significant. The difference between the coefficients is also statistically significant.

Looking at the dry season, the main impacts are again concentrated on the first two trimesters of pregnancy. We find no significant effect for the last trimester, and a borderline significant effect for the trimester immediately before conception. Curiously, for the rainy 
season we do find some statistically significant impact in the last trimester, but the effect is quantitatively smaller than those estimated for the dry season. None of the other coefficients is statistically significant in the rainy season regression.

This pattern of results confirms that we are capturing indeed the effect of water scarcity during the gestational period. In fact, the table highlights the relevance of availability of water during the moments of early development of the embryo and formation of organs (first two trimesters of gestation). For births in the dry season, a low precipitation in the previous 12 months means that, during pregnancy, the little reserves of water collected before are already at low levels and, therefore, of poor quality. These would increase the probability of infectious diseases and dehydration for the mother, affecting the health of the fetus.

In Table 6, we look at the moment of realization of mortality. We analyze variation in rainfall both in the 12 months before birth and by trimester of gestation. Our dependent variables are mortality rates in different time frames after birth: (i) the first 24 hours of life; (ii) from 24 hours to 3 months; (iii) from 3 to 6 months; (iv) from 6 to 9 months; and (v) from 10 to 12 months.

Given the higher frequency of mortality being analyzed, some of the coefficients are estimated with less precision. Also, quantitative comparisons of the coefficient related to mortality in the first 24 hours should bear in mind that its time interval is much shorter than the other ones. The results indicate a borderline statistically significant coefficient for mortality during the first day of life, and statistically significant effects for mortality in the first 6 months of life. After 6 months, the coefficient becomes smaller in magnitude and ceases to be statistically significant. Consistent with the effects being concentrated in the first months of life, the coefficient drops even further when we look at the period between 10 and 12 months.

The coefficient in column 1 - related to mortality in the first day of life - is extremely large in magnitude, but imprecisely estimated (on a monthly basis, it would be of the order of -30). The profile of results suggests, therefore, that the effects of rainfall during gestation are concentrated in the period immediately after birth, and tend to become less relevant as the child survives the first six months of life. Once more, this reinforces the evidence that the conditions faced in utero - and not after birth - are indeed the driving force behind our results. The results broken down by trimester of gestation in Table 6 show again that the fetal development period (second trimester) seems particularly important, with significant effects appearing also in the embryogenesis period (first trimester) for mortality in the first 3 months of life. 
Despite the absence of mortality impacts after six months of life, the effects detected before on birth weight and length of gestation suggest that water scarcity can still have long run impacts on morbidity and cognitive development. These are extremely relevant issues, but are again beyond the scope of this paper.

\subsection{Channels}

Our final effort is to present evidence on the specific channels linking fluctuations in rainfall to health outcomes at birth. In the context of the Brazilian semiarid, there are two main potential connections in this relationship. First, water scarcity may be associated with lower agricultural production and, therefore, lower nutrient intake. Second, it may be associated with lack of access to safe drinkable water and, therefore, higher incidence of infectious diseases. The evidence presented up to now suggests that lack of access to safe drinkable water is likely to be an important factor, but still leaves space for some effect through agricultural production.

In order to address this issue directly, Table 7 presents two sets of exercises. First, in Panel A, we run the benchmark specification from column 4 in Table 2 controlling for municipality agricultural production per capita. In the first column, we control for agricultural production in the 12 months before birth, the same time frame used for our rainfall variable. In the second column, we control for agricultural production in the period between 12 and 24 months before birth (year before conception), while in column 3 we control for agricultural production in the first year of life. Finally, in column 4, we include the three agricultural production variables simultaneously. ${ }^{8}$

Irrespective of how we introduce agricultural production in the regression, there is virtually no change in the coefficient associated with rainfall before birth. The coefficient actually increases slightly in magnitude when the three agricultural production variables are included simultaneously. Agricultural production, in turn, does not appear as statistically significant. Panel A suggests that the estimated impact of rainfall variation on health at birth is not driven by local agricultural production and nutrient availability.

\footnotetext{
${ }^{8}$ Our agricultural production data have, in reality, an yearly frequency. We construct monthly data based on the weighted average of production across consecutive years. So, for example, for an individual born in March, agricultural production in the 12 months prior to birth will be 0.3 times agricultural production in the year of birth plus 0.7 times agricultural production in the year before birth. Though this is only a rough approximation to the actual production during the relevant months, it does capture movements in agricultural production around the time of birth. Issues of the specific timing of production are dealt with in column 4 of the table, where we introduce agricultural production in the three consecutive years around birth simultaneously.
} 
In Panel B, we look at the heterogeneity of the estmated impact by municipality characteristics. The literature highlights that water scarcity should be a particularly serious health issue when sanitation and water services are poorly developed. To evaluate whether this link is present in our results, in column 1 we interact rainfall before birth with municipality coverage of public water services in the year 2000. In column 2, we repeat the same exercise for sanitation coverage. Still, it is possible that sanitation and piped water are just capturing the overall level of development in the municipality. So, in column 3, we repeat again the same exercise using municipality income per capita and, in column 4, we include the three interaction terms simultaneously.

Columns 1 to 3 show a similar pattern for the three municipality characteristics considered. There is a negative impact of rainfall variation on infant mortality, but this effect is reduced for municipalities with higher coverage of piped water, converging to close to zero as water coverage reaches $100 \%$. Exactly the same pattern is present for sanitation coverage and income per capita. These first results suggest that municipalities with better public health infrastructure and higher income per capita are less subject to variations in mortality due to rainfall shocks. But this pattern is consistent both with a direct effect of public health infrastructure and with an effect of overall economic development.

When we look at the three interaction terms simultaneously, in column 4, none of them is individually significant. This should be expected, given the high degree of collinearity among them. Still, the net effects calculated from column 4 are very enlightening. We have three dimensions of variation here, so net effects should be calculated conditional on a certain fraction of piped water and sanitation coverages, and on a given level of income per capita. In order to summarize the results, Table 8 calculates the net effect of rainfall variation on infant mortality at different levels of the three municipality characteristics. Panel A is conditioned on income per capita at the $25^{t h}$ percentile of the distribution, Panel B on income per capita at the $50^{t h}$ percentile, and Panel $\mathrm{C}$ at the $75^{\text {th }}$ percentile. Within each panel, rows indicate different fractions of households covered by public sanitation and columns indicated coverage of piped water (from $0 \%$ to $100 \%$ ). Moving from panel to panel, one can see how the effect of rainfall variation changes with income per capita, for given levels of piped water and sanitation coverage. Moving within a panel across columns, one can see how the effect changes with piped water coverage, for given levels of sanitation and income per capita. And moving across rows, one can see how the effect changes with sanitation coverage, for given piped water coverage and income per capita.

The first thing to come out of the table is that, though higher income seems to be 
associated with lower impact of rainfall variation - as when we move from Panel A to Panel $\mathrm{C}$ - the heterogeneity is very mild when compared to changes in sanitation and piped water coverages. In other words, the within panel variation in net effects is larger than the variation across panels. For example, municipalities with $40 \%$ coverages of piped water and sanitation have a net effect of -10.55 if they are on the $25^{\text {th }}$ percentile of income per capita, and of -8.50 if they are on the $75^{\text {th }}$ percentile.

The joint effect of piped water and sanitation coverages, in contrast, is much larger. For municipalities with the median income per capita, a movement in sanitation and water coverages from $20 \%$ to $80 \%$ leads to a reduction in the net effect of rainfall from -11.46 to -5.95 (and only borderline statistically significant). Similar patterns are observed for other levels of income per capita. A sufficiently high coverage of piped water seems to be, in isolation, the most important factor in determining reductions in the impact of rainfall. Irrespective of income per capita or sanitation, access to piped water has a substantial impact on the response to rainfall shocks. Still, it is true that the effects of access to water and sanitation combined lead to the greatest reductions in the responsiveness of infant mortality to rainfall.

These results are remarkably consistent with a vast literature on the health impacts of access to water (see, for example, Mara (2003), United Nations Development Programme (2006), Fewtrell et al. (2007), World Health Organization (2010), World Health Organization (2012), Pond et al. (2011)). All this body of work highlights that the health implications of water scarcity should be particularly severe in contexts of poor coverage of sanitation and water services. The pattern encountered in Table 8, therefore, reinforces the idea that the results obtained thus far are indeed driven by access to safe drinkable water.

Quantitatively, the results from this section mean that a variation in rainfall from the $90^{t h}$ to the $10^{t h}$ percentile would lead to an increase in infant mortality of 6.3 points for a

municipality with a $20 \%$ coverage of piped water and sanitation. For a municipality with universal coverage of these public goods, the response of infant mortality to a similar shock would be only 2.3 points (and not statistically significant). Increased access to water and sanitation would therefore lead to a reduction in the response to the negative shock of the order of 4 deaths per 1,000 births.

\subsection{Cost-Benefit Analysis}

The results from Tables 7 and 8 provide inputs that can be directly used in a cost-benefit analysis. From these numbers, one can estimate the potential benefits in terms of infant mortality from expanding the coverage of piped water and sanitation systems in the Brazilian 
semiarid. We conduct this exercise using information from the 2000 census. The perspective, therefore, is that of a policy maker in the year 2000, considering the potential costs and benefits of expanding coverage of water and sanitation services.

This quantitative exercise is not entirely straightforward because it requires the choice a reference point to calculate the infant mortality rate in the counterfactual scenario where mortality does not respond to rainfall shocks. By comparing this number with the infant mortality rate generated by a given rainfall pattern, one can then calculate the excess mortality attributable to rainfall.

We take as reference point the $95^{\text {th }}$ percentile of the log-deviation of rainfall in the sample, because it indicates the level of mortality observed in a scenario where water scarcity is unlikely to be an issue. Given the low levels of rainfall in the semiarid Northeast, it would seem reasonable to use as benchmark an even higher incidence of rainfall, corresponding to more usual conditions from the perspective of the rest of the country (the highest rainfall shocks in the semiarid hardly ever reach the usual levels observed in the remainder of Brazil). Strictly, the natural hypothesis would be that, if there was no response of infant mortality to rainfall, the mortality level observed would be that corresponding to the highest level of rainfall in the sample. We use the $95^{\text {th }}$ percentile instead to generate a conservative estimate.

Using the historical pattern of rainfall variation from 1938 to 2000 and the coefficients estimated before, it is possible to calculate the average "excess" mortality that would be observed under different coverages of water and sanitation. With those numbers in hand, it is straightforward to calculate the role of expanded coverage in reducing this "excess" mortality. Finally, number of births can then be used to generate the yearly number of lives saved from a given expansion in the system.

On the cost side, the Technical Note SNSA \#492/2010, from the Brazilian Ministry of Cities (see Brazilian Ministry of Cities (2011)), provides numbers on the costs of expansion in the piped water and sanitation systems in Brazil, by region and number of households to be covered. Combining these with municipality data on household coverages from the 2000 census, we can estimate the total cost of universalization of water and sanitation in the semiarid Northeast. This is the cost-benefit exercise we conduct in this section.

Table 9 presents the results from this exercise. Panel A shows the numbers on coverage and respective costs. In 2000, over 1.6 million households (or 36\%) did not have access to treated water in the semiarid region, and over 2 million (or 44\%) did not have sanitation. The cost of universalization of water coverage in the region would amount to a total of $\mathrm{R} \$ 3.3$ billion (or US\$ 1.66 billion, at an exchange rate of roughly $2 \mathrm{R} \$ / \mathrm{US} \$$ ) and that of sanitation 
would be roughly $\mathrm{R} \$ 8.9$ billion (or US $\$ 4.45$ billion). Universalization of both public goods would therefore cost a total of $\mathrm{R} \$ 12.2$ billion.

The benefits from universalization are presented in Panel B. Expanding piped water coverage in the semiarid to $100 \%$ would save an average of 454 lives per year, while the same expansion in sanitation would save 242 lives. To value this yearly flow of lives saved, we calculate what would have to be the value of a statistical life in order to make these benefits exactly match the costs listed in Panel A. We do these calculations using different interest rates and assuming that the future percentage change in number of births in a municipality is equal to the average percentage change observed in the region between 2000 and 2008. We call the values obtained from this calculation the break even values of a statistical life: under a given interest rate scenario, any value of a statistical life higher than that obtained in the calculation would justify universalization.

The table shows that any value of a statistical life above $\mathrm{R} \$ 688,000$ (or US $\$ 344,000$ ) would justify universalization of piped water coverage, irrespective of the interest rate. The numbers for sanitation are somewhat higher: under a $2.5 \%$ interest rate, a value of $R \$ 1$ million would be needed to justify the investment, while under a $10 \%$ interest rate the value would be $\mathrm{R} \$ 3.5$ million. A justified universalization of both services would require a value of a statistical life above $\mathrm{R} \$ 500,000$ considering a $2.5 \%$ interest rate, and above $\mathrm{R} \$ 1.66$ million considering a $10 \%$ interest rate.

Preliminary estimates of the value of a statistical life for Brazil generated values ranging from $\mathrm{R} \$ 650,000$ to $\mathrm{R} \$ 5$ million (in $2010 \mathrm{R} \$$, see Corbi et al. (2006)). Numbers estimated for other developing countries - such as India, South Korea, and Taiwan - usually fall within a similar range (Viscusi and Aldy (2003)). Taking the lower end of this interval, any interest rate below $10 \%$ would lead to a strictly positive valuation for the universalization of water coverage. Any mid-range combination of these extreme estimates would also be enough to justify the joint expansion of piped water and sanitation to $100 \%$ coverage. Sanitation alone, in turn, is not such a clearly cost effective intervention from the perspective of infant mortality considered here.

\section{Concluding Remarks}

This paper presents evidence of a negative relationship between water scarcity during the gestational period and health at birth. We identify shocks to water scarcity by exploring rainfall fluctuations in the semiarid region of Northeastern Brazil. We also provide estimates 
on the important role of piped water and sanitation coverage in minimizing the susceptibility of a given population to rainfall fluctuations.

The strategy outlined here provides numbers that can be used in cost-benefit analyses of expansions in public health infrastructure. Water scarcity is a major problem for a large fraction of the rural population in the developing world. Climate change is likely to make it an even more recurrent phenomenon. Our results suggests that cost-benefit considerations support the adoption of a preventive strategy focused on expanding the access to treated water and sanitation. Short run minimization of impacts during episodes of adverse shocks should target maternal health and large scale rehydration strategies.

\section{References}

Ab'Sáber, A. (1999). Sertões e Sertanejos: uma Geografia Humana Sofrida. Estudos Avancados, 13:7-59.

Aguilar, A. and Vicarelli, M. (2011). El Nino and Mexican Children: Medium-term Effects of Early-Life Weather Shocks on Cognitive and Health Outcomes. Unpublished Manuscript.

Almond, D. and Currie, J. (2010). Human Capital Development Before Age Five. NBER Working Paper n. 15827.

Áridas, P. (1995). Nordeste: Uma Estratégia de Desenvolvimento Sustentável. Ministerio da Integracao Nacional.

Barker, D. (1998a). In Utero Programming of Chronic Disease. Clinical Science, 95(2):115128.

Barker, D. (1998b). Mothers, Babies, and Health in Later Life. Elsevier Health Sciences.

Barron, W. (1987). Water Metabolism and Vasopressin Secretion During Pregnancy. Baillière's Clinical Obstetrics and Gynaecology, 1(4):853.

Black, R., Allen, L., Bhutta, Z., Caulfield, L., De Onis, M., Ezzati, M., Mathers, C., and

Rivera, J. (2008). Maternal and Child Undernutrition: Global and Regional Exposures and Health Consequences. Lancet, 371(9608):243-260.

Bloomfield, F. and Harding, J. (1998). Experimental Aspects of Nutrition and Fetal Growth. Fetal and Maternal Medicine Review, 10(02):91-107. 
Bloomfield, F., Oliver, M., and Harding, J. (2006). The Late Effects of Fetal Growth Patterns. British Medical Journal, 91(4):F299.

Bongaarts, J. (1980). Does Malnutrition Affect Fecundity? A Summary of Evidence. Science, 208(4444):564-569.

Bozzoli, C., Deaton, A., and Quintana-Domeque, C. (2009). Adult Height and Childhood Disease. Demography, 46(4):647-669.

Brown, K. and Dewey, K. (1992). Mechanisms Regulating Lactation and Infant Nutrient Utilization, chapter Relationships Between Maternal Nutritional Status and Milk Energy Output of Women in Developing Countries, pages 99-77. New York: Wiley-Liss.

Burgess, R., Deschenes, O., Donaldson, D., and Greenstone, M. (2011). Weather and Death in India. Unpublished Manuscript.

Campos, J. N. B. (1994). Vulnerabilidade do Semi-Arido as Secas Sob o Ponto de Vista dos Recursos Hidricos. Projeto Aridas.

Cirilo, J. (2008). Políticas Públicas de Recursos Hídricos para o Semi-árido. Estudos Avançados, 22(63):61.

Corbi, R., Menezes-Filho, N., Soares, R., and da Costa Werlang, S. (2006). Avaliação Econômica de Ganhos Sociais na Área da Saúde-Estimativas do Valor de uma Vida Estatística para o Brasil. Unpublished Manuscript.

Currie, J. (2009). Healthy, Wealthy, and Wise: Socioeconomic Status, Poor Health in Childhood, and Human Capital Development. Journal of Economic Literature, 47(1):87-122.

Deschenes, O., Greenstone, M., and Guryan, J. (2009). Climate Change and Birth Weight. American Economic Review: Papers and Proceedings, 99(2):211-217.

Deschenes, O. and Moretti, E. (2009). Extreme Weather Events, Mortality, and Migration. The Review of Economics and Statistics, 91(4):659-681.

Fewtrell, L., Prüss-Üstün, A., Bos, R., Gore, F., Bartram, J., et al. (2007). Water, Sanitation and Hygiene: Quantifying the Health Impact at National and Local Levels in Countries with Incomplete Water Supply and Sanitation Coverage. WHO Environmental Burden of Disease Series, (15). 
Friedman, G. (1982). The Heights of Slaves in Trinidad. Social Science History, 6(4):482-515.

Frisch, R. (1978). Population, Food Intake, and Fertility. Science, 199(4324):22-30.

Glewwe, P. W. and Miguel, E. A. (2008). The Impact of Child Health and Nutrition on Education in Less Developed Countries. In Schultz, T. P. and Strauss, J. A., editors, The Handbook of Development Economics, volume 4, chapter 56, pages 3561-3606. Elsevier, 1 edition.

Gorgens, T., Meng, X., and Vaithianathan, R. (2011). Stunting and Selection Effects of Famine: A Case Study of the Great Chinese Famine. Journal of Development Economics. Forthcoming.

Kim, Y. (2010). The Impact of Rainfall on Early Child Health. Unpublished Manuscript.

Kudamatsu, M., Persson, T., and Stromberg, D. (2010). Weather and Infant Mortality in Africa. Unpublished Manuscript.

Linnet, K., Wisborg, K., Agerbo, E., Secher, N., Thomsen, P., and Henriksen, T. (2006). Gestational Age, Birth Weight, and the Risk of Hyperkinetic Disorder. Archives of Disease in Childhood, 91(8):655.

Luna, R. M. (2007). Desenvolvimento do Indice de Pobreza Hidrica (IPH) para o Semiarido Brasileiro. Master's thesis, Universidade Federal do Ceara.

Maccini, S. and Yang, D. (2009). Under the Weather: Health, Schooling, and Economic Consequences of Early-Life Rainfall. American Economic Review, 99(3):1006-1026.

Mara, D. (2003). Water, Sanitation and Hygiene for the Health of Developing Nations. Public Health, 117(6):452-456.

Matsuura, K. and Willmott, C. (2009). Terrestrial Air Temperature and Precipitation: 1900-2008 Gridded Monthly Time Series, Version 1.02. University of Delaware.

Morgane, P., Austin-LaFrance, R., Bronzino, J., Tonkiss, J., Diaz-Cintra, S., Cintra, L., Kemper, T., and Galler, J. (1993). Prenatal Malnutrition and Development of the Brain. Neuroscience \& Biobehavioral Reviews, 17(1):91-128.

Parry, M., Canziani, O., Palutikof, J., Van Der Linden, P., and Hanson, C. (2007). IPCC, 2007: Climate Change 200\%: Impacts, Adaptation and Vulnerability. Contribution of 
Working Group II to the Fourth Assessment Report of the Intergovernmental Panel on Climate Change. Cambridge University Press, UK.

Pond, K., Pedley, S., and Edwards, C. (2011). Background Chapter In: Cameron, J. and Hunter, P. and Jagals, P. and Pond, K., Valuing Water, Valuing Livelihoods. London: IWA Publishing.

Rebouças, A. (1997). Água na Região Nordeste: Desperdício e Escassez. Estudos Avançados, 11(29):127-154.

Ross, M. and Desai, M. (2005). Gestational programming: Population survival effects of drought and famine during pregnancy. American Journal of Physiology-Regulatory, Integrative and Comparative Physiology, 288(1):R25-R33.

Shenkin, S., Starr, J., and Deary, I. (2004). Birth Weight and Cognitive Ability in Childhood: a Systematic Review. Psychological Bulletin, 130:989-1011.

Skoufias, E., Vinha, K., and Conroy, H. (2011). The Impacts of Climate Variability on Welfare in Rural Mexico. World Bank Policy Research Working Paper, 5555.

Sobsey, M. (2002). Managing Water in the Home: Accelerated Health Gains from Improved Water Supply. World Health Organization.

Steegers-Theunissen, R. (1995). Maternal Nutrition and Obstetric Outcome. Baillière's Clinical Obstetrics and Gynaecology, 9(3):431-443.

SUDENE (1981). As Secas do Nordeste: Uma Abordagem Historica de Causas e Efeitos. SUDENE, Ministerio do Interior.

SUDENE (2008). Nova Delimitacao da Regiao Semi-arida do Brasil. SUDENE, Recife.

Suliano, D., Magalhaes, K., and Soares, R. (2009). A Influencia do Clima no Desempenho da Economia Cearense. IPECE, Texto para Discusso n.56.

United Nations Development Programme (2006). Human Development Report 2006. Beyond Scarcity: Power, Poverty and the Global Water Crisis. Palgrave Macmillan.

Villa, M. (2000). Vida e Morte no Sertao: Historias das Secas no Nordeste nos Seculos XIX e XX. Atica. 
Viscusi, W. and Aldy, J. (2003). The Value of a Statistical Life: a Critical Review of Market Estimates Throughout the World. Journal of Risk and Uncertainty, 27(1):5-76.

World Bank (2008). World Development Report 2008: Agriculture For Development. World Bank, Washington.

World Health Organization (2010). UN-Water Global Annual Assessment of Sanitation and Drinking-water: GLAAS 2010: Targeting Resources for Better Results. World Health Organization, Geneva.

World Health Organization (2012). Drought: Natural Disaster Profiles. World Health Organization, Geneva. 
Figure 1 - Yearly Precipitation in Brazilian Semiarid Northeast and in the Rest of the Country

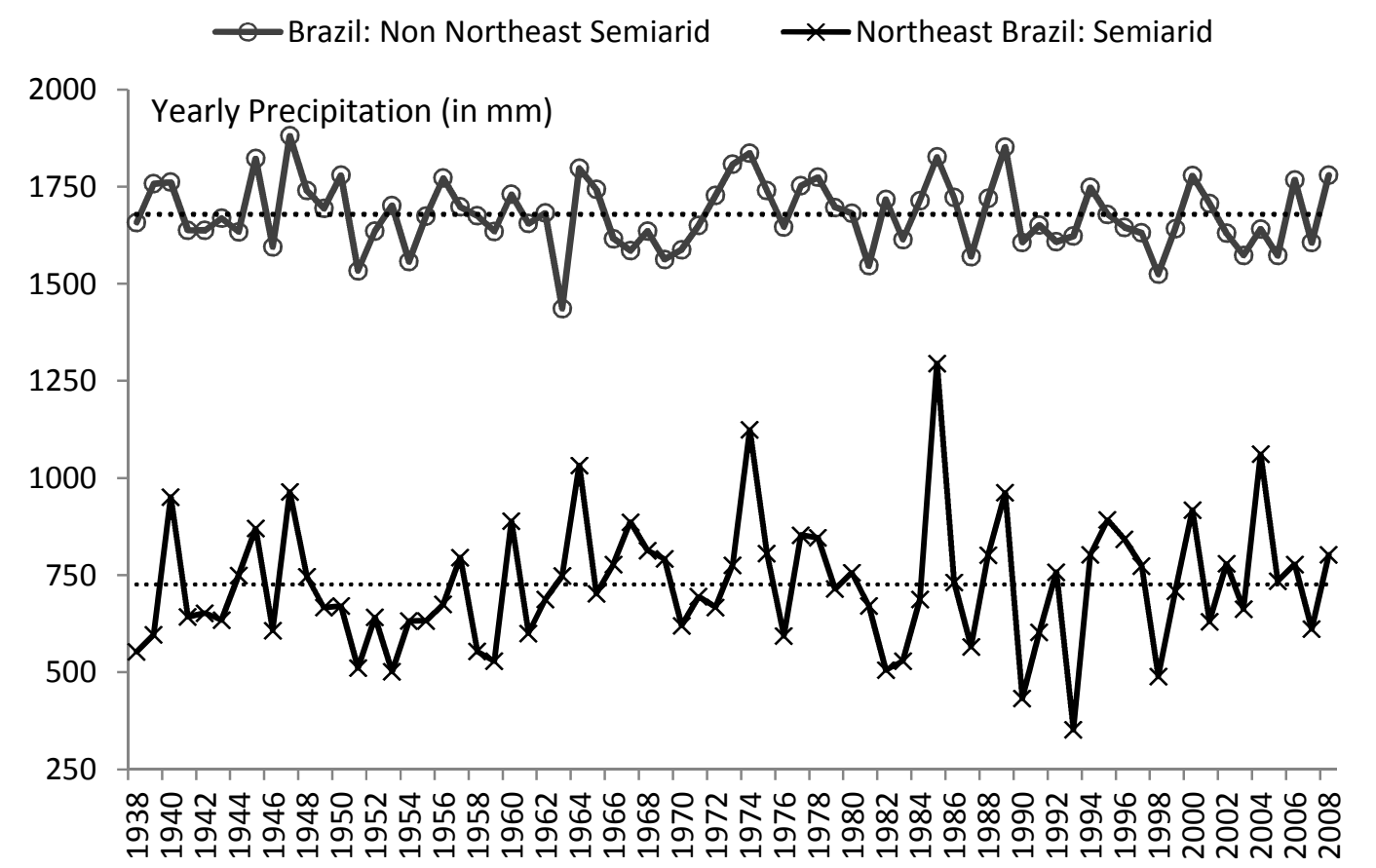

Notes: Author's calculation based on data from the Terrestrial Air Temperature and Precipitation: 1900-2008 Gridded Monthly Time Series, Version 1.02. 
Figure 2 - Monthly Rainfall in the Brazilian Semiarid Northeast, Historical Averages

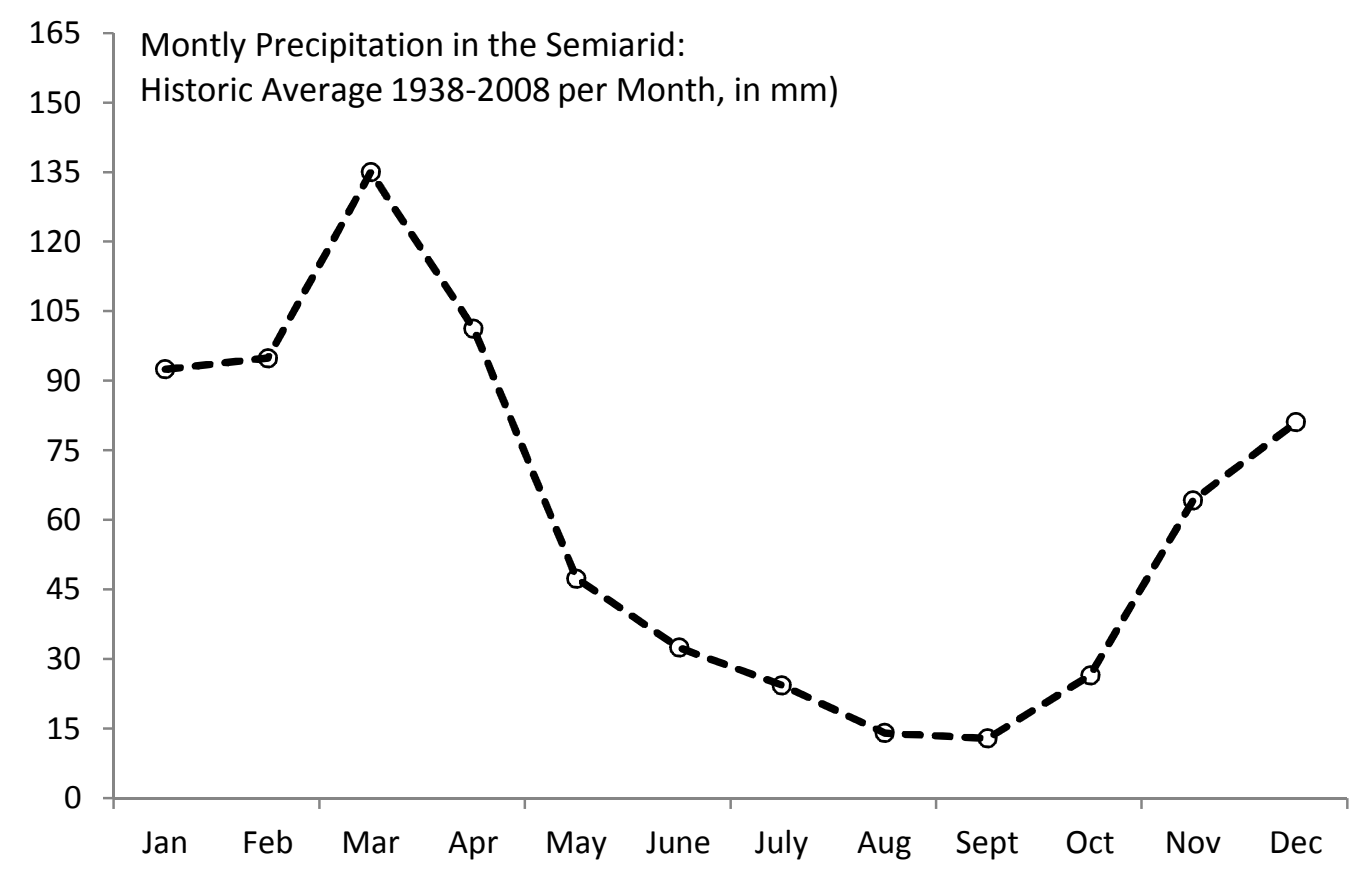

Notes: Municipality averages. Author's calculation based on data from the Terrestrial Air Temperature and Precipitation: 19002008 Gridded Monthly Time Series, Version 1.02. 
Figure 3 - Rainfall Idiosyncratic Fluctuations Across Time and Place in the Northeast Semiarid

Panel A - Deviation of Log Rainfall in the Past 12 Months from the Avg.

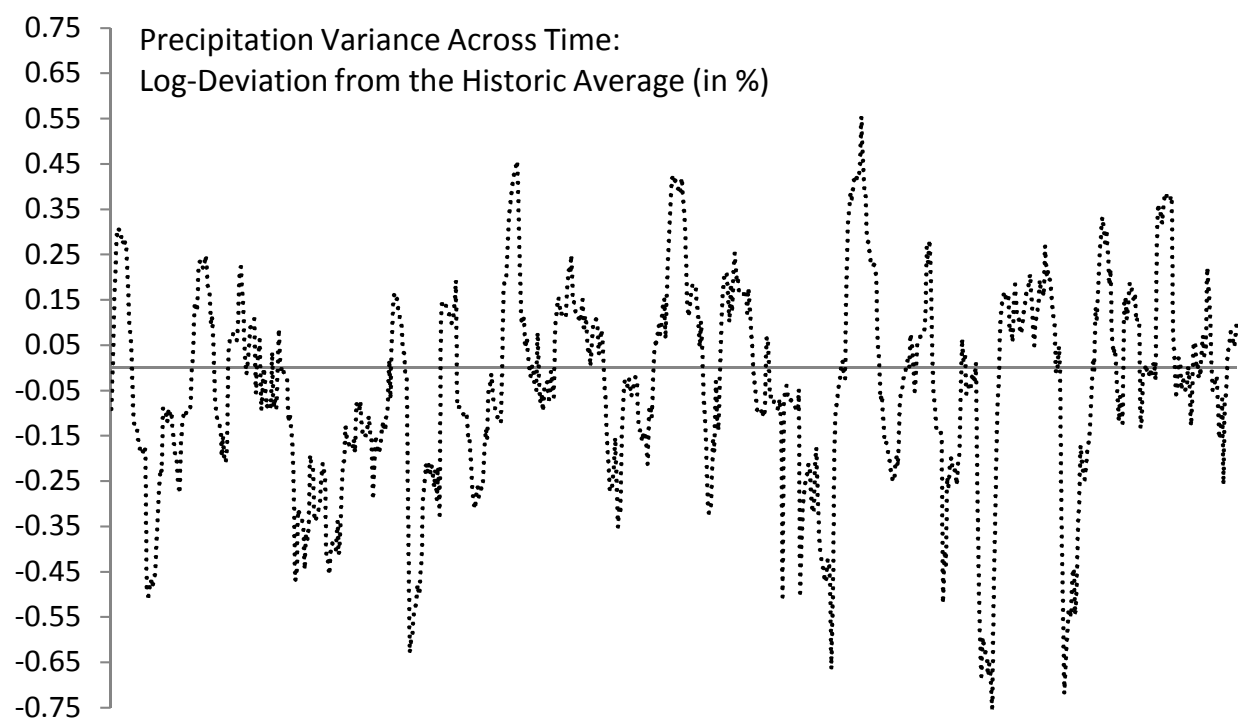

원

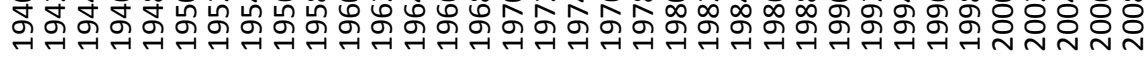

Panel B - Drought Indicator (Rainfall in the Past 12 Months Below 1 SD the Avg.)

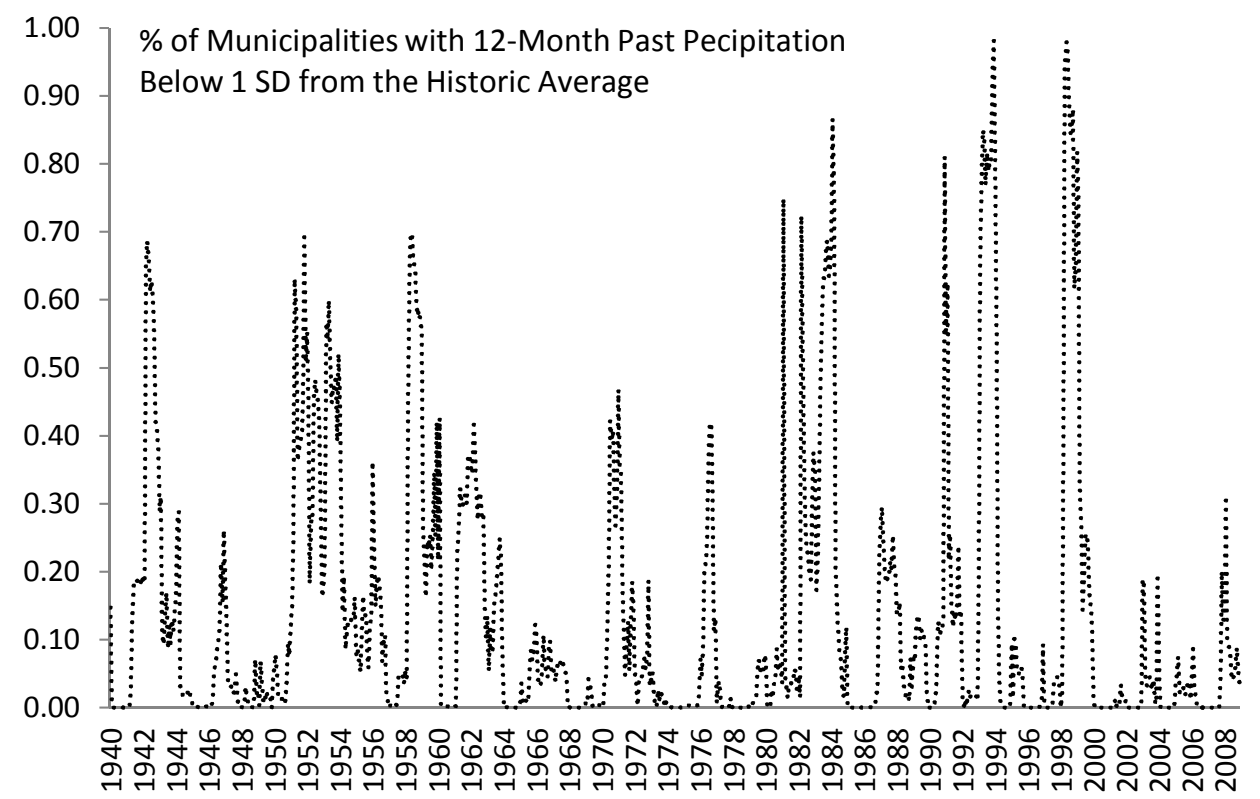

Notes: Municipality averages. Author's calculation based on data from the Terrestrial Air Temperature and Precipitation: 1900-2008 Gridded Monthly Time Series, Version 1.02. 
Figure 4 - Seasonal Infant Mortality and Fertility: Drought vs Non Drought Month of Birth
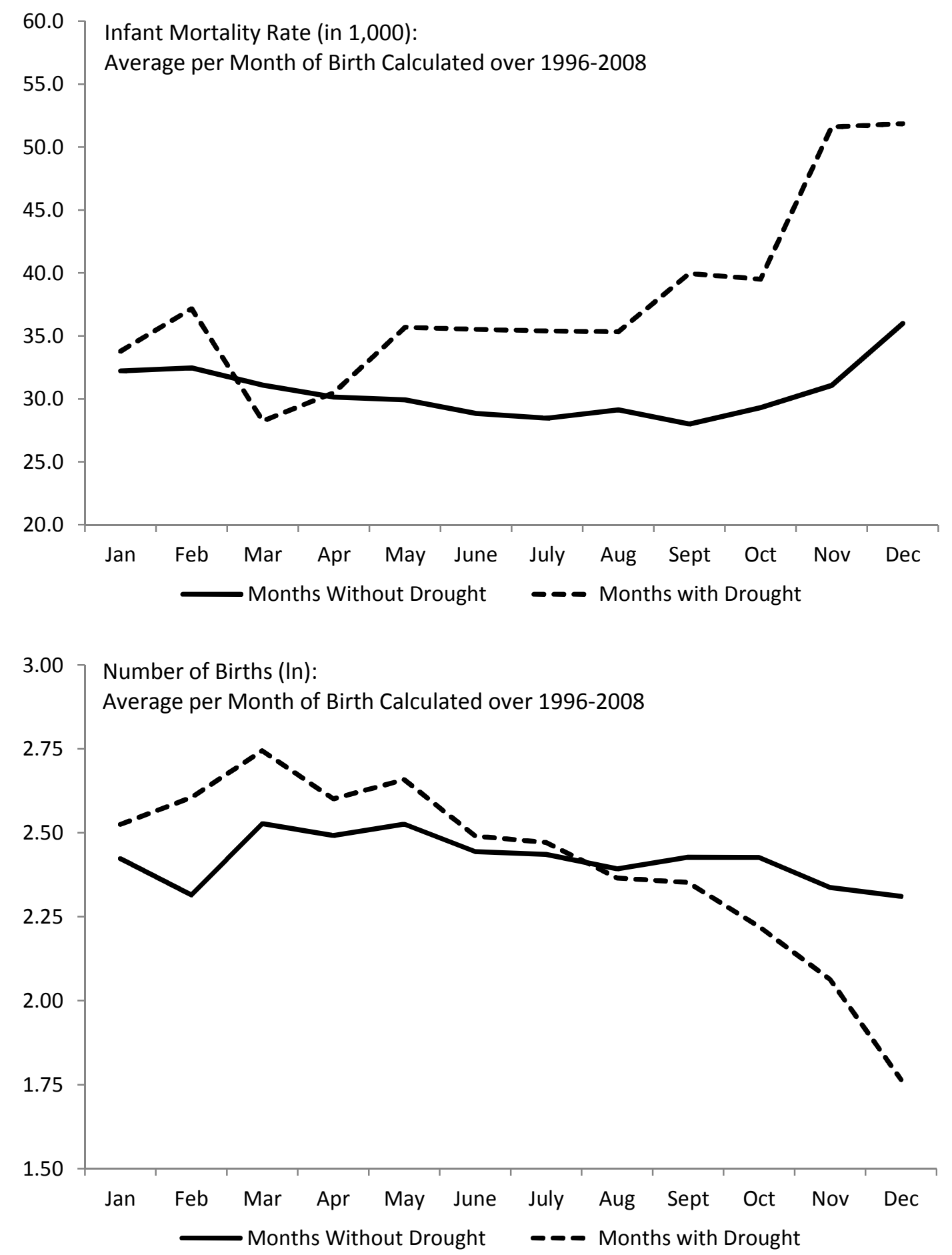

Notes: Municipality averages. Author's calculation based on data from the Terrestrial Air Temperature and Precipitation: 19002008 Gridded Monthly Time Series, Version 1.02. 
Table 1 - Summary Statistics: Monthly Municipality Data 1996-2008, Semiarid Region in Northeastern Brazil

\begin{tabular}{|c|c|c|c|c|c|c|}
\hline Variables & Mean & $\begin{array}{c}\text { Std. } \\
\text { Deviation }\end{array}$ & Min & Max & $\begin{array}{c}\text { Number of } \\
\text { Municipalities }\end{array}$ & $\begin{array}{c}\text { Number of } \\
\text { Observations }\end{array}$ \\
\hline
\end{tabular}

Births and Health Indicators per Month of Birth:

Number of Births

Birth Weight

28.9

3271

0.94

52.4

$\%$ of Births Occurring after 36 Weeks of Gestation

Number of Infant Deaths

207

0.13

2.05
31.26

31.26

1.09

1.97

14.02

2.28

7.37

Congenital Malformations

Non Reported Causes

Rainfall Indicators per Month:

Rainfall in the Past 12 Months (in $\mathrm{mm}$ )

Rainfall Log-Deviation in the Past 12 Months

Drought in the Past 12 Months

$\begin{array}{lllll}82.63 & 0 & 1000 & 1048 & 157403 \\ 29.51 & 0 & 1000 & 1048 & 157403 \\ 16.48 & 0 & 1000 & 1048 & 157403 \\ 21.48 & 0 & 1000 & 1048 & 157403 \\ 51.88 & 0 & 1000 & 1048 & 157403 \\ 20.56 & 0 & 1000 & 1048 & 157403 \\ 45.89 & 0 & 1000 & 1048 & 157403\end{array}$

163488

157222

157200

163488 
Table 2 - Fixed-Effects Panel Regressions: Impact of Rainfall Fluctuations on Infant Mortality Rates; Monthly Municipality Data 1996-2008, Semiarid Region in Northeastern Brazil

\section{(1)}

(2)
(3)

(4)
(5)

Panel A - Rainfall

Rainfall before Birth

$-4.486$

$(1.290)^{* * *}$

$-4.759$

$(1.297)^{* * *}$

$-7.034$

$-7.139$

$-8.405$

Rainfall 12-24 Months before Birth

$(1.642)^{* * *}$

$(1.828)^{* * *}$

$(2.438)^{* * *}$

$-1.878$

(2.368)

$-3.370$

(2.700)

Panel B - Drought

Drought before Birth

2.087

$(1.118)^{*}$

2.265

3.984

3.761

4.594

Rainfall 12-24 Months before Birth

$(1.109)^{* *}$

$(1.299)^{* * *}$

$(1.324)^{* * *}$

$(1.620)^{* * *}$

$-0.771$

(2.327)

$-2.224$

(2.469)

Rainfall 1-12 Months after Birth

\begin{tabular}{|c|c|c|c|c|c|}
\hline Observations & 157,403 & 155,688 & 155,688 & 155,688 & 143,319 \\
\hline Number of Municipalities & 1,048 & 1,037 & 1,037 & 1,037 & 1,037 \\
\hline Municipality $\times$ Month of Birth Fixed Effects & Yes & Yes & Yes & Yes & Yes \\
\hline Year of Birth Fixed Effects & Yes & Yes & Yes & Yes & Yes \\
\hline Grid Time Trend & Yes & Yes & Yes & Yes & Yes \\
\hline Exclude Top $1 \%$ in Number of Births & No & Yes & Yes & Yes & Yes \\
\hline Weighted (Average Number of Newborns) & No & No & Yes & Yes & Yes \\
\hline Temperature before Birth & No & No & No & Yes & Yes \\
\hline
\end{tabular}




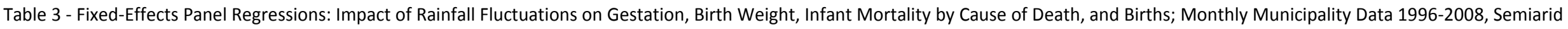
Region in Northeastern Brazil

\begin{tabular}{|c|c|c|c|c|c|c|c|c|c|}
\hline \multirow{2}{*}{$\begin{array}{c}\text { Birth } \\
\text { Weight }\end{array}$} & \multirow{2}{*}{$\begin{array}{l}\text { Gestation } \\
>37 \text { weeks }\end{array}$} & \multicolumn{6}{|c|}{ Infant Mortality Rate per Cause of Death } & \multirow{2}{*}{$\begin{array}{l}\text { In(Number } \\
\text { of Births) }\end{array}$} & \multirow{2}{*}{$\begin{array}{r}\text { Sex } \\
\text { Ratio }\end{array}$} \\
\hline & & Intestinal & Malnutrition & Respiratory & Perinatal & Congenital & Non Reported & & \\
\hline (1) & & (3) & (4) & (5) & (6) & (7) & (8) & (9) & (10) \\
\hline
\end{tabular}

Rainfall before Birth

$\begin{array}{cccccc}6.462 & 0.019 & -3.877 & -1.289 & -0.814 & -1.707 \\ (2.607)^{* *} & (0.003)^{* * *} & (0.897)^{* * *} & (0.430)^{* * *} & (0.458)^{*} & (1.065)\end{array}$

Panel A - Rainfall

$(0.003)^{* * *}$

$(0.897) * * * \quad(0.430) * * *$

$(0.458)^{*}$

(1.065)

0.014

(0.281)

-2.148
$(0.747)^{* * *}$

0.059

0.001

Panel B - Drought

Drought before Birth

$\begin{array}{cc}-4.348 & -0.010 \\ (2.127)^{* *} & (0.003)^{* * *} \\ & \\ 155,507 & 155,485 \\ 1,037 & 1,037 \\ \text { Yes } & \text { Yes } \\ \text { Yes } & \text { Yes } \\ \text { Yes } & \text { Yes } \\ \text { Yes } & \text { Yes } \\ \text { Yes } & \text { Yes }\end{array}$

2.250
$(0.591)^{* * *}$
155,688
1,037
Yes
Yes
Yes
Yes
Yes

$\begin{array}{cc}0.346 & 0.585 \\ (0.198)^{*} & (0.335)^{*} \\ & \\ 155,688 & 155,688 \\ 1,037 & 1,037 \\ \text { Yes } & \text { Yes } \\ \text { Yes } & \text { Yes } \\ \text { Yes } & \text { Yes } \\ \text { Yes } & \text { Yes } \\ \text { Yes } & \text { Yes }\end{array}$

0.706
$(0.807)$
155,688
1,037
Yes
Yes
Yes
Yes
Yes

-0.075
$(0.223)$
155,688
1,037
Yes
Yes
Yes
Yes
Yes

0.953
$(0.570)^{*}$
155,688
1,037
Yes
Yes
Yes
Yes
Yes

$\begin{array}{cc}-0.053 & -0.000 \\ (0.023)^{* *} & (0.001) \\ 161,772 & 155,688 \\ 1,037 & 1,037 \\ \text { Yes } & \text { Yes } \\ \text { Yes } & \text { Yes } \\ \text { Yes } & \text { Yes } \\ \text { Yes } & \text { Yes } \\ \text { Yes } & \text { Yes }\end{array}$

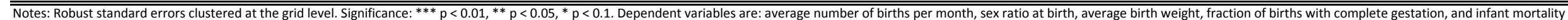

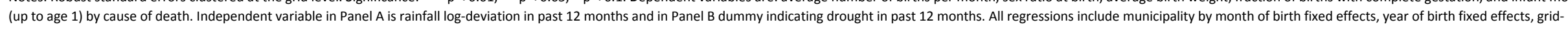
specific linear time trends, average temperature in 12 months before birth, exclude municipalities with average number of births per month in the top 1\%, and are weighted by municipality average number of births per month. 
Table 4 - Fixed-Effects Panel Regressions: Impact of Rainfall Fluctuations on Infant Health by Gender; Monthly Municipality Data 1996-2008, Semiarid Region in Northeastern Brazil

\begin{tabular}{|c|c|c|c|c|c|c|c|c|c|c|}
\hline & \multirow{2}{*}{$\begin{array}{c}\text { Infant } \\
\text { Mortality }\end{array}$} & \multirow{2}{*}{$\begin{array}{c}\text { Birth } \\
\text { Weight }\end{array}$} & \multirow{2}{*}{$\begin{array}{l}\text { Gestation } \\
>37 \text { weeks }\end{array}$} & \multicolumn{6}{|c|}{ Infant Mortality Rate per Cause of Death } & \multirow{2}{*}{$\begin{array}{l}\text { In(Number } \\
\text { of Births) }\end{array}$} \\
\hline & & & & Intestinal & Malnutrition & Respiratory & Perinatal & Congenital & Non Reported & \\
\hline & (1) & $(2)$ & (3) & $(4)$ & $(6)$ & (7) & (8) & (9) & $(10)$ & $(11)$ \\
\hline & \multicolumn{10}{|c|}{ Panel A - Boys } \\
\hline \multirow[t]{2}{*}{ Rainfall before Birth } & -6.080 & 1.974 & 0.018 & -2.234 & -0.558 & -0.428 & -0.465 & 0.310 & -1.957 & 0.062 \\
\hline & $(1.526)^{* * *}$ & $(3.025)$ & $(0.003)^{* * *}$ & $(0.705)^{* * *}$ & $(0.296)^{*}$ & $(0.428)$ & $(0.911)$ & $(0.305)$ & $(0.900)^{* *}$ & $(0.032)^{* *}$ \\
\hline \multirow[t]{2}{*}{ Observations } & 151,691 & 151,361 & 151,265 & 151,691 & 151,691 & 151,691 & 151,691 & 151,691 & 151,691 & 161,772 \\
\hline & \multicolumn{10}{|c|}{ Panel B - Girls } \\
\hline \multirow[t]{2}{*}{ Rainfall before Birth } & -9.067 & 10.614 & 0.019 & -3.231 & -1.110 & -0.567 & -2.126 & -0.333 & -2.440 & 0.051 \\
\hline & $(1.636)^{* * *}$ & $(3.096)^{* * *}$ & $(0.003)^{* * *}$ & $(0.745)^{* * *}$ & $(0.403)^{* * *}$ & $(0.355)$ & $(0.815)^{* * *}$ & $(0.313)$ & $(0.760)^{* * *}$ & $(0.031)$ \\
\hline Observations & 151,145 & 150,815 & 150,715 & 151,145 & 151,145 & 151,145 & 151,145 & 151,145 & 151,145 & 161,772 \\
\hline Number of Municipalities & 1,037 & 1,037 & 1,037 & 1,037 & 1,037 & 1,037 & 1,037 & 1,037 & 1,037 & 1,037 \\
\hline Municipality $\times$ Month of Birth FE & Yes & Yes & Yes & Yes & Yes & Yes & Yes & Yes & Yes & Yes \\
\hline Year of Birth FE & Yes & Yes & Yes & Yes & Yes & Yes & Yes & Yes & Yes & Yes \\
\hline Temperature Control and Grid Trends & Yes & Yes & Yes & Yes & Yes & Yes & Yes & Yes & Yes & Yes \\
\hline Weighted (Average N. of Newborns) & Yes & Yes & Yes & Yes & Yes & Yes & Yes & Yes & Yes & Yes \\
\hline Exclude Top $1 \%$ in Number of Births & Yes & Yes & Yes & Yes & Yes & Yes & Yes & Yes & Yes & Yes \\
\hline
\end{tabular}

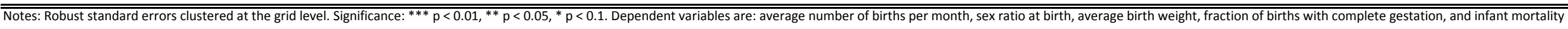

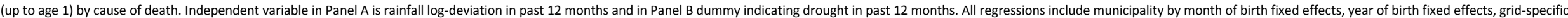
linear time trends, average temperature in 12 months before birth, exclude municipalities with average number of births per month in the top 1\%, and are weighted by municipality average number of births per month. 
Table 5 - Fixed-Effects Panel Regressions: Impact of Rainfall Fluctuations by Trimester of Gestation and Season; Monthly Municipality Data 19962008, Semiarid Region in Northeastern Brazil

\begin{tabular}{cccccc}
\hline \multicolumn{4}{c}{ Mortality } \\
\cline { 2 - 6 } & $(1)$ & $(2)$ & $(3)$ & $(4)$ & $(5)$ \\
\hline \hline
\end{tabular}

All Year (Jan-Dec) Born in Rainy Season (Jan-June)

Rainfall before Birth

Rainfall by Trimester of Gestation: 3rd Trimester (Perinatal)

0.049

(0.383)

2nd Trimester (Fetal)

$-2.147$

$(0.501)^{* * *}$

$-0.751$

1st Trimester (Embryonic)

Trimester before Conception

$(0.274)^{* * *}$

$-0.162$

(0.303)

\begin{tabular}{ccc}
155,688 & 77,925 & 77,925 \\
1,037 & 1,037 & 1,037 \\
Yes & Yes & Yes \\
Yes & Yes & Yes \\
Yes & Yes & Yes \\
Yes & Yes & Yes \\
Yes & Yes & Yes \\
\hline
\end{tabular}

$-3.235$

(2.345)
$-1.680$
$(0.675)^{* *}$
$-0.751$
(0.402)*
$-0.115$
(0.279)
0.048

(0.536)

\section{Observations}

Number of Municipalities

Municip $\times$ Month of Birth FE

Year of Birth FE

Temperature Control and Grid Trends

Exclude Top $1 \%$ in Number of Births

Weighted (Average N. of Newborns)

Yes

Born in Dry Season (July-Dec)

$-10.922$

$(3.092)^{* * *}$

0.343

$-2.506$

$(0.963)^{* * *}$

$-2.332$

$(0.787)^{* * *}$

$-1.103$

$(0.648)^{*}$

77,763
1,037
Yes
Yes
Yes
Yes
Yes

77,763

1,037

Yes

Yes

Yes

Yes

Yes

(est Robust standard errors clustered at the grid level. Significance: ${ }^{* * *} p<0.01, * * p<0.05,{ }^{*} p<0.1$. Dependent variables are infant mortality (up to age 1 ) and average number of births per month. Independent variables are rainfall log-deviation by trimester of gestation and season of birth: rainfall fluctuation per trimester calculated as deviations of the sum of rainfall in each trimester from its historical average; columns 3-6 include only children born from January to June (rainy season); columns 7-10 include those born from July to December (dry season). All regressions include municipality by month of birth fixed effects, year of birth fixed effects, grid-specific linear time trends, average temperature in 12 months before birth, exclude municipalities with average number of births per month in the top $1 \%$, and are weighted by municipality average number of births per month. 
Table 6 - Fixed-Effects Panel Regressions: Impact of Rainfall Fluctuations by Trimester of Gestation and Timing of Death; Monthly Municipality Data 1996-2008, Semiarid Region in Northeastern Brazil

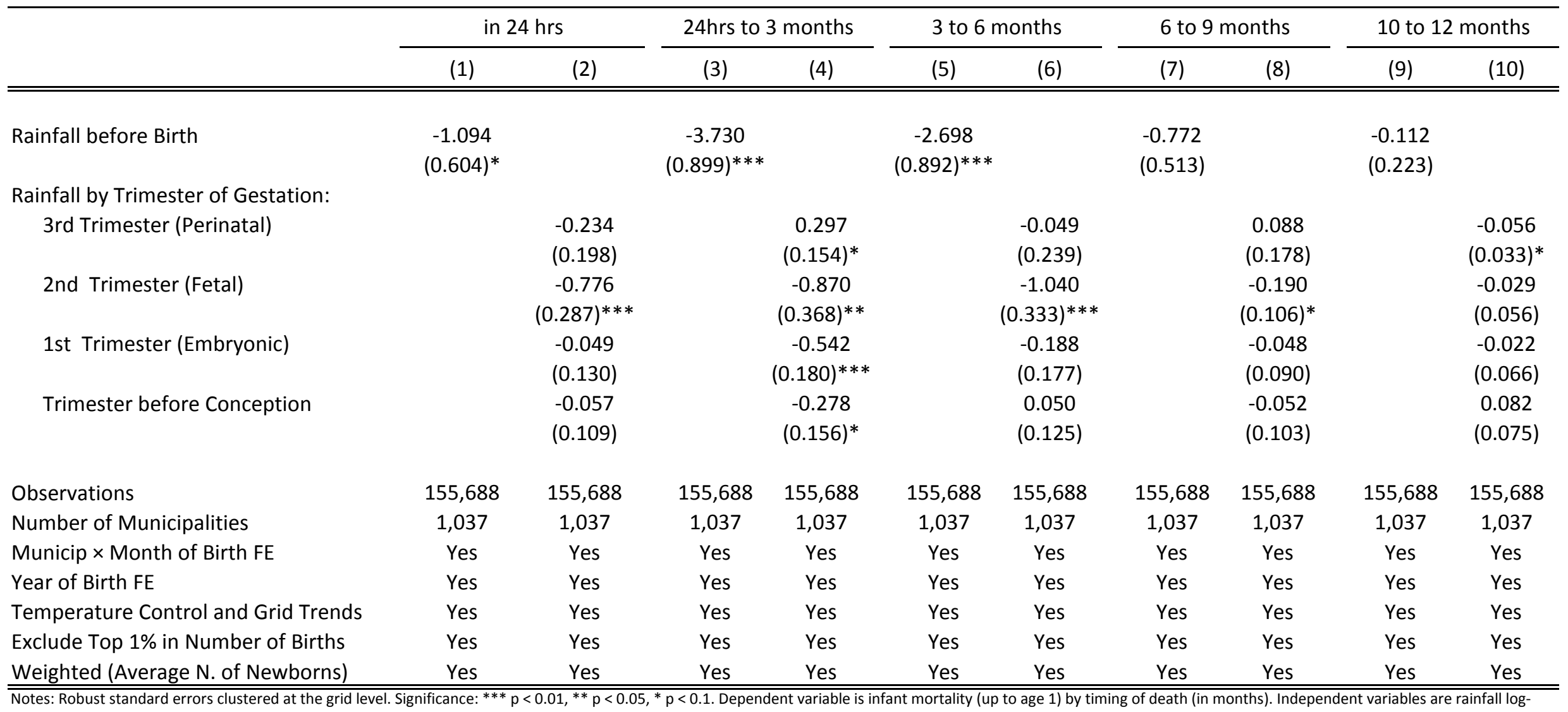

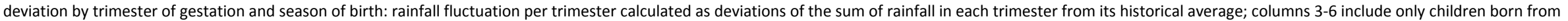

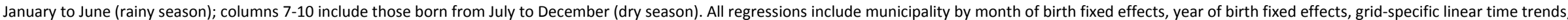
average temperature in 12 months before birth, exclude municipalities with average number of births per month in the top $1 \%$, and are weighted by municipality average number of births per month. 
Table 7 - Fixed-Effects Panel Regressions: Channels in the Impact of Rainfall Fluctuations on Infant Mortality; Monthly Municipality Data 1996-2008, Semiarid Region in Northeastern Brazil

\begin{tabular}{|c|c|c|c|c|}
\hline & \multicolumn{4}{|c|}{ Infant Mortality Rate } \\
\hline & (1) & $(2)$ & (3) & (4) \\
\hline & \multicolumn{4}{|c|}{ Panel A } \\
\hline \multirow[t]{2}{*}{ Rainfall before Birth } & -7.003 & -7.271 & -7.616 & -7.700 \\
\hline & $(1.799)^{* * *}$ & $(1.868)^{* * *}$ & $(2.145)^{* * *}$ & $(2.182)^{* * *}$ \\
\hline \multirow[t]{2}{*}{ Agricultural Production before Birth } & -0.431 & & & -0.459 \\
\hline & $(0.785)$ & & & $(0.852)$ \\
\hline \multirow[t]{2}{*}{ Agricultural Production 12-24 Months before Birth } & & -0.675 & & -0.822 \\
\hline & & $(0.807)$ & & $(0.854)$ \\
\hline \multirow[t]{2}{*}{ Agricultural Production 1-12 Months after Birth } & & & 0.826 & 0.987 \\
\hline & & & $(1.087)$ & $(1.124)$ \\
\hline Observations & 155,666 & 155,673 & 143,297 & 143,292 \\
\hline \multirow[t]{2}{*}{ Number of Municipalities } & 1,037 & 1,037 & 1,037 & 1,037 \\
\hline & \multicolumn{4}{|c|}{ Panel B } \\
\hline \multirow[t]{2}{*}{ Rainfall before Birth } & -15.648 & -14.934 & -48.783 & -37.808 \\
\hline & $(3.117)^{* * *}$ & $(3.373)^{* * *}$ & $(13.969)^{* * *}$ & $(17.478)^{* *}$ \\
\hline \multirow[t]{2}{*}{ Rainfall before Birth $\times \%$ Water Coverage } & 14.384 & & & 6.411 \\
\hline & $(4.745)^{* * *}$ & & & $(6.255)$ \\
\hline \multirow[t]{2}{*}{ Rainfall before Birth $\times \%$ Sanitation Coverage } & & 14.611 & & 2.764 \\
\hline & & $(5.472)^{* * *}$ & & (8.125) \\
\hline \multirow[t]{2}{*}{ Rainfall before Birth $\times \ln ($ Income per Capita) } & & & 9.215 & 5.619 \\
\hline & & & $(3.040)^{* * *}$ & $(4.462)$ \\
\hline Observations & 155,688 & 155,549 & 155,688 & 155,549 \\
\hline Number of Municipalities & 1,037 & 1,036 & 1,037 & 1,036 \\
\hline Municip $\times$ Month of Birth FE & Yes & Yes & Yes & Yes \\
\hline Temperature Control and Grid Trends & Yes & Yes & Yes & Yes \\
\hline Exclude Top $1 \%$ in Number of Births & Yes & Yes & Yes & Yes \\
\hline Weighted (Average N. of Newborns) & Yes & Yes & Yes & Yes \\
\hline Sample: \% of Rural Households & All & All & All & All \\
\hline
\end{tabular}

Notes: Robust standard errors clustered at the grid level. Significance: ${ }^{* * *} p<0.01,{ }^{* *} p<0.05,{ }^{*} p<0.1$. Dependent variable is infant mortality (before age 1). Independent variable is rainfall log-deviation in past 12 months. In Panel A, agricultural production control is log of weighted average of the value of agricultural production per capita in the year of birth (calendar month of birth/12) and the previous year ((12 - calendar month of birth)/12). Lagged and lead values are calculated analogously. In Panel B, rainfall before birth is interacted with: municipality share of households with water and sanitation coverage, and log of the income per capita (calculated from the 2000 Census files). All regressions include municipality by month of birth fixed effects, year of birth fixed effects, grid-specific linear time trends, average temperature in 12 months before birth, exclude municipalities with average number of births per month in the top $1 \%$, and are weighted by municipality average number of births per month. In column 5 , sample restricted to municipalities with more than $50 \%$ of households in rural areas (calculated from 2000 Census files). 
Table 8 - Heterogeneous Effects of Rainfall Variation on Infant Mortality, by Income p.c., Water and Sanitation Coverage (Based on Coefficients from Table 7, Column 4 in Panel B)

\begin{tabular}{|c|c|c|c|c|c|c|c|}
\hline \multirow{11}{*}{ 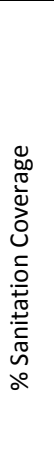 } & & \multicolumn{6}{|c|}{ Panel A - Income p.c. at the $25^{\text {th }}$ percentile } \\
\hline & & & & $\%$ Wate & overage & & \\
\hline & \multirow[b]{2}{*}{0} & 0 & 0.2 & 0.4 & 0.6 & 0.8 & 1 \\
\hline & & -14.22 & -12.94 & -11.65 & -10.37 & -9.09 & -7.81 \\
\hline & 0.2 & $\begin{array}{c}(14.21)^{* * *} \\
-13.67\end{array}$ & $\begin{array}{c}(13.22)^{* * *} \\
-12.38\end{array}$ & $\begin{array}{c}(9.55)^{* * *} \\
-11.10\end{array}$ & $\begin{array}{c}(5.69)^{* *} \\
-9.82\end{array}$ & $\begin{array}{c}(3.09)^{*} \\
-8.54\end{array}$ & $\begin{array}{l}(1.62) \\
-7.26\end{array}$ \\
\hline & & $(19.77) * * *$ & $(23.82)^{* * *}$ & $(18.79)^{* * *}$ & $(9.83)^{* * *}$ & $(4.50)^{* *}$ & $(2.05)$ \\
\hline & 0.4 & -13.11 & -11.83 & -10.55 & -9.27 & -7.98 & -6.70 \\
\hline & 0.6 & $\begin{array}{c}(17.29)^{* * *} \\
-12.56\end{array}$ & $\begin{array}{c}(25.46)^{* * *} \\
-11.28\end{array}$ & $\begin{array}{c}(26.61)^{* * *} \\
-10.00\end{array}$ & $\begin{array}{c}(14.32)^{* * *} \\
-8.71\end{array}$ & $\begin{array}{c}(5.83)^{* *} \\
-7.43\end{array}$ & $\begin{array}{l}(2.36) \\
-6.15\end{array}$ \\
\hline & 0.8 & $\begin{array}{c}(10.03)^{* * *} \\
-12.01\end{array}$ & $\begin{array}{c}(12.93)^{* * *} \\
-10.73\end{array}$ & $\begin{array}{c}(14.10)^{* * *} \\
-9.44\end{array}$ & $\begin{array}{c}(10.18)^{* * *} \\
-8.16\end{array}$ & $\begin{array}{c}(5.04)^{* *} \\
-6.88\end{array}$ & $\begin{array}{l}(2.15) \\
-5.60\end{array}$ \\
\hline & 1 & $\begin{array}{c}(5.38)^{* *} \\
-11.45\end{array}$ & $\begin{array}{c}(5.91)^{* *} \\
-10.17\end{array}$ & $\begin{array}{c}(5.84)^{* *} \\
-8.89\end{array}$ & $\begin{array}{c}(4.69)^{* *} \\
-7.61\end{array}$ & $\begin{array}{l}(2.91)^{*} \\
-6.33\end{array}$ & $\begin{array}{l}(1.46) \\
-5.04\end{array}$ \\
\hline & & $(3.04)^{*}$ & $(3.01)^{*}$ & $(2.75)^{*}$ & $(2.21)$ & (1.49) & $(0.83)$ \\
\hline
\end{tabular}

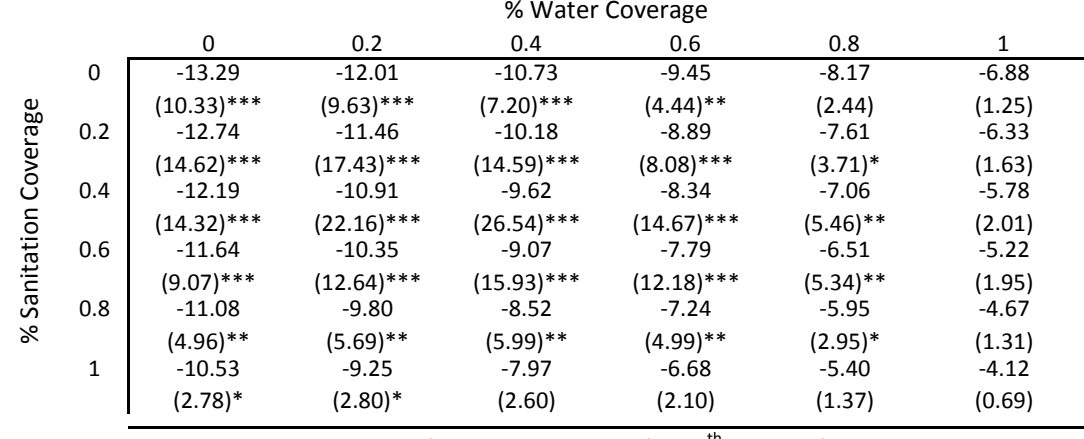

Panel C - Income p.c. at the $75^{\text {th }}$ percentile

\begin{tabular}{|c|c|c|c|c|c|c|}
\hline \multirow{9}{*}{ 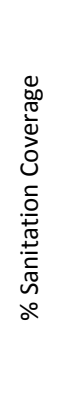 } & 0 & 0.2 & 0.4 & 0.6 & 0.8 & 1 \\
\hline & -12.17 & -10.89 & -9.61 & -8.33 & -7.05 & -5.76 \\
\hline & $\begin{array}{l}(6.73)^{* * *} \\
-11.62\end{array}$ & $\begin{array}{l}(6.17)^{* *} \\
-10.34\end{array}$ & $\begin{array}{c}(4.72)^{* *} \\
-9.06\end{array}$ & $\begin{array}{c}(3.01)^{*} \\
-7.78\end{array}$ & $\begin{array}{l}(1.68) \\
-6.49\end{array}$ & $\begin{array}{l}(0.85) \\
-5.21\end{array}$ \\
\hline & $(9.29)^{* * *}$ & $(10.38)^{* * *}$ & $(8.93)^{* * *}$ & $(5.40)^{* *}$ & (2.58) & (1.10) \\
\hline & -11.07 & -9.79 & -8.50 & -7.22 & -5.94 & -4.66 \\
\hline & $\begin{array}{c}(9.94)^{* * *} \\
-10.52\end{array}$ & $\begin{array}{c}(14.41)^{* * * *} \\
-9.23\end{array}$ & $\begin{array}{c}(17.66)^{* * *} \\
-7.95\end{array}$ & $\begin{array}{c}(11.16)^{* * *} \\
-6.67\end{array}$ & $\begin{array}{c}(4.21)^{* *} \\
-5.39\end{array}$ & $\begin{array}{l}(1.43) \\
-4.11\end{array}$ \\
\hline & $\begin{array}{c}(7.18)^{* * *} \\
-9.96\end{array}$ & $\begin{array}{c}(10.30)^{* * *} \\
-8.68\end{array}$ & $\begin{array}{c}(14.75)^{* * *} \\
-7.40\end{array}$ & $\begin{array}{c}(12.98) * * * \\
-6.12\end{array}$ & $\begin{array}{c}(5.10)^{* * *} \\
-4.84\end{array}$ & $\begin{array}{l}(1.52) \\
-3.55\end{array}$ \\
\hline & $\begin{array}{c}(4.18)^{* *} \\
-9.41\end{array}$ & $\begin{array}{c}(4.96)^{* *} \\
-8.13\end{array}$ & $\begin{array}{c}(5.61)^{* *} \\
-6.85\end{array}$ & $\begin{array}{c}(5.02)^{* *} \\
-5.56\end{array}$ & $\begin{array}{l}(2.82)^{*} \\
-4.28\end{array}$ & $\begin{array}{l}(1.03) \\
-3.00\end{array}$ \\
\hline & (2.37) & $(2.41)$ & (2.29) & $(1.85)$ & (1.13) & $(0.48)$ \\
\hline
\end{tabular}
household water and sanitation converage. The coefficients (direct and interaction effects) and standard-errors used in the calculations correspond to the specification displayed in Table 7, Column 4 of Panel B. 
Table 9 - Cost-Benefit Analysis for Number of Lives Saved, 2000 Census as Benchmark

\begin{tabular}{|c|c|c|c|c|c|}
\hline & \multicolumn{5}{|c|}{ Panel A: Costs } \\
\hline & \multirow{2}{*}{$\begin{array}{c}\text { Total \# of Households } \\
\text { without Coverage }\end{array}$} & \multirow{2}{*}{$\begin{array}{c}\text { Fraction of } \\
\text { Households without } \\
\text { Coverage }\end{array}$} & \multicolumn{3}{|c|}{ Cost of Moving to $100 \%$ Coverage } \\
\hline & & & $\begin{array}{c}\text { Avg Cost per } \\
\text { Household Covered } \\
\text { (in } \mathrm{R} \$ \text { ) }\end{array}$ & $\begin{array}{l}\text { Avg Municipality Cost } \\
\text { (in Million } \mathrm{R} \$ \text { ) }\end{array}$ & $\begin{array}{c}\text { Total Cost } \\
\text { (in Billion } \mathrm{R} \$ \text { ) }\end{array}$ \\
\hline Water & $1,687,178$ & $36 \%$ & 1,963 & 3.16 & 3.31 \\
\hline Sanitation & $2,069,577$ & $44 \%$ & 4,306 & 8.51 & 8.91 \\
\hline \multirow[t]{5}{*}{ Water + Sanitation } & & & 6,269 & 11.67 & 12.23 \\
\hline & \multicolumn{5}{|c|}{ Panel B: Benefits } \\
\hline & \multirow[t]{3}{*}{ Lives Saved per Year } & \multicolumn{4}{|c|}{ Break Even Value of a Statistical Life } \\
\hline & & $r=0.025$ & $r=0.05$ & $r=0.075$ & $r=0.1$ \\
\hline & & \multicolumn{4}{|c|}{ (in Thousand R\$) } \\
\hline Water & 454 & 207 & 375 & 535 & 688 \\
\hline Sanitation & 242 & 1,050 & 1,900 & 2,711 & 3,485 \\
\hline Water + Sanitation & 696 & 499 & 904 & 1,290 & 1,658 \\
\hline
\end{tabular}

Notes: Numbers on cost calculated using cost estimates from the Technical Note SNSA \# 492/2010, from the Brazilian Ministry of Cities, and numbers on coverage from the 2000 census.

Numbers on benefits calculated using the coefficients from Table 7, Column 4 of Panel B. Values in $2010 \mathrm{R} \$$ (exchange rate to the US\$ of approximately 2 R\$/US\$). 


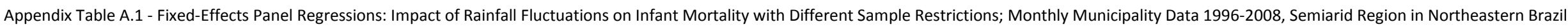

\begin{tabular}{|c|c|c|c|c|c|c|c|c|}
\hline & Excluding 1996 & Excluding 1997 & $\begin{array}{c}\text { Excluding } 1996 \& \\
1997\end{array}$ & $\begin{array}{c}\text { Excluding } 3 \text { States } \\
\text { with Highest \# of } \\
\text { Missing (PI, CE \& BA) }\end{array}$ & $\begin{array}{l}\text { Excluding } 3 \text { States } \\
\text { with Highest \# of } \\
\text { Missing (PI, CE \& BA) } \\
\text { and } 1996 \text { \& } 1997\end{array}$ & $\begin{array}{c}\text { Excluding } \\
\text { Municipalities } \\
\text { without Registered } \\
\text { Births in } 1996\end{array}$ & $\begin{array}{c}\text { Excluding } \\
\text { Municipalities } \\
\text { without Registered } \\
\text { Births in Any Year }\end{array}$ & $\begin{array}{c}\text { Using Number of } \\
\text { Deaths as } \\
\text { Dependent Variables }\end{array}$ \\
\hline & (1) & (2) & (3) & (4) & (5) & (6) & (7) & $(8)$ \\
\hline Rainfall before Birth & $\begin{array}{c}-8.018 \\
(2.022)^{* * *}\end{array}$ & $\begin{array}{c}-3.879 \\
(1.536)^{* *}\end{array}$ & $\begin{array}{c}-4.522 \\
(1.437)^{* * *}\end{array}$ & $\begin{array}{c}-5.489 \\
(1.804)^{* * *}\end{array}$ & $\begin{array}{c}-5.653 \\
(1.551)^{* * *}\end{array}$ & $\begin{array}{c}-7.167 \\
(1.874)^{* * *}\end{array}$ & $\begin{array}{c}-7.164 \\
(1.874)^{* * *}\end{array}$ & $\begin{array}{c}-0.385 \\
(0.078)^{* * *}\end{array}$ \\
\hline Observations & 145,794 & 144,984 & 135,090 & 75,716 & 65,115 & 134,988 & 134,860 & 161,772 \\
\hline Number of Municipalities & 1,037 & 1,037 & 1,037 & 501 & 501 & 877 & 876 & 1,037 \\
\hline Municipality $\times$ Month of Birth FE & Yes & Yes & Yes & Yes & Yes & Yes & Yes & Yes \\
\hline Year of Birth FE & Yes & Yes & Yes & Yes & Yes & Yes & Yes & Yes \\
\hline Temperature Control and Grid Trends & Yes & Yes & Yes & Yes & Yes & Yes & Yes & Yes \\
\hline Weighted (Average N. of Newborns) & Yes & Yes & Yes & Yes & Yes & Yes & Yes & Yes \\
\hline Exclude Top $1 \%$ in Number of Births & Yes & Yes & Yes & Yes & Yes & Yes & Yes & Yes \\
\hline
\end{tabular}

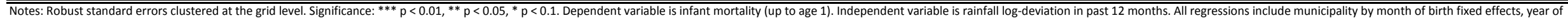

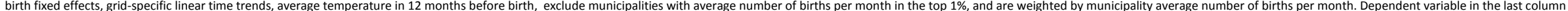
number of deaths. In other columns, sample is restricted according to what is described in the column title. 
Appendix Table A.2 - Fixed-Effects Panel Regressions: Impact of Rainfall Fluctuations on Infant Mortality and Number of Births by Precipitation Thresholds; Monthly Municipality Data 1996-2008, Semiarid Region in Northeastern Brazil

\begin{tabular}{|c|c|c|}
\hline & Infant Mortality & In(Number of Births) \\
\hline & (1) & $(2)$ \\
\hline \multicolumn{3}{|l|}{ Total Rainfall before Birth: } \\
\hline \multirow{2}{*}{ Up to $400 \mathrm{~mm}$} & 8.534 & -0.177 \\
\hline & $(2.725)^{* * *}$ & $(0.058)^{* * *}$ \\
\hline \multirow[t]{2}{*}{$400 \mathrm{~mm}$ to $600 \mathrm{~mm}$} & 5.774 & -0.047 \\
\hline & $(2.105)^{* * *}$ & $(0.030)$ \\
\hline \multirow[t]{2}{*}{$600 \mathrm{~mm}$ to $800 \mathrm{~mm}$} & 2.643 & -0.014 \\
\hline & $(2.040)$ & $(0.027)$ \\
\hline \multirow[t]{2}{*}{$800 \mathrm{~mm}$ to $1000 \mathrm{~mm}$} & 3.534 & -0.074 \\
\hline & $(2.016)^{*}$ & $(0.031)^{* *}$ \\
\hline \multirow[t]{2}{*}{$1000 \mathrm{~mm}$ to $1200 \mathrm{~mm}$} & -1.181 & -0.033 \\
\hline & $(2.065)$ & $(0.023)$ \\
\hline Observations & 155.688 & 161,772 \\
\hline Number of Municipalities & 1,037 & 1,037 \\
\hline Municip $\times$ Month of Birth FE & Yes & Yes \\
\hline Year of Birth FE & Yes & Yes \\
\hline Temperature Control and Grid Trends & Yes & Yes \\
\hline Exclude Top $1 \%$ in Number of Births & Yes & Yes \\
\hline Weighted (Average N. of Newborns) & Yes & Yes \\
\hline \multicolumn{3}{|c|}{$\begin{array}{l}\text { Notes: Robust standard errors clustered at the grid level. Significance: }{ }^{* * *} p<0.01,{ }^{* *} p<0.05,{ }^{*} p<0.1 \text {. Dependent } \\
\text { variables are infant mortality (up to age } 1 \text { ) and average number of births per month. Independent variables are } \\
\text { dummies indicating total amount of rainfall (in } \mathrm{mm} \text { ) in past } 12 \text { months. All regressions include municipality by month } \\
\text { of birth fixed effects, year of birth fixed effects, grid-specific linear time trends, average temperature in } 12 \text { months } \\
\text { before birth, exclude municipalities with average number of births per month in the top } 1 \% \text {, and are weighted by } \\
\text { municipality average number of births per month. }\end{array}$} \\
\hline
\end{tabular}

